\title{
Sound-Assisted Fluidization for Temperature Swing Adsorption and Calcium Looping: A Review
}

\author{
Federica Raganati (1) and Paola Ammendola* \\ Istituto di Scienze e Tecnologie per l'Energia e la Mobilità Sostenibili (STEMS)—CNR, P.le V. Tecchio, \\ 80125 Napoli, Italy; federica.raganati@stems.cnr.it \\ * Correspondence: paola.ammendola@irc.cnr.it; Tel.: +39-0817-6822-37
}

check for

updates

Citation: Raganati, F.; Ammendola, P. Sound-Assisted Fluidization for Temperature Swing Adsorption and Calcium Looping: A Review. Materials 2021, 14, 672. https:// doi.org/10.3390/ma14030672

Academic Editor: Carlos Javier DuranValle

Received: 30 December 2020

Accepted: 28 January 2021

Published: 1 February 2021

Publisher's Note: MDPI stays neutral with regard to jurisdictional clai$\mathrm{ms}$ in published maps and institutional affiliations.

Copyright: (C) 2021 by the authors. Licensee MDPI, Basel, Switzerland. This article is an open access article distributed under the terms and conditions of the Creative Commons Attribution (CC BY) license (https:// creativecommons.org/licenses/by/ $4.0 /)$.

\begin{abstract}
Fine/ultra-fine cohesive powders find application in different industrial and chemical sectors. For example, they are considered in the framework of the Carbon Capture and Storage (CCS), for the reduction of the carbon dioxide emissions to the atmosphere, and in the framework of the thermochemical energy storage (TCES) in concentrated solar power (CSP) plants. Therefore, developing of technologies able to handle/process big amounts of these materials is of great importance. In this context, the sound-assisted fluidized bed reactor (SAFB) designed and set-up in Naples represents a useful device to study the behavior of cohesive powders also in the framework of low and high temperature chemical processes, such as $\mathrm{CO}_{2}$ adsorption and Ca-looping. The present manuscript reviews the main results obtained so far using the SAFB. More specifically, the role played by the acoustic perturbation and its effect on the fluid dynamics of the system and on the performances/outcomes of the specific chemical processes are pointed out.
\end{abstract}

Keywords: sound-assisted fluidization; cohesive fine/ultra-fine particles; Carbon Capture and Storage (CCS); $\mathrm{CO}_{2}$ adsorption/desorption; temperature swing adsorption (TSA); thermochemical energy storage (TCES); calcium looping

\section{Introduction}

Fine and ultra-fine powders, i.e., characterized by particle size lower than $30 \mu \mathrm{m}$, have been characterized by increased research interest in recent years. In fact, due to their exceptional properties, mainly derived from their characteristic dimensions and large surface area per unit mass (which means that they are able to offer larger contact/reaction efficiency), they can be applied in a variety of industrial sectors, such as in the production of foods, plastics, cosmetics, catalysts, and metallurgic components [1].

For instance, nanostructured catalysts, characterized by a hierarchical porosity, have been synthesized in the framework of different chemical processes, such as combustion and gasification and fuel and polymer production [2]. Likewise, fine/ultrafine particles have also found application in the Carbon Capture and Storage (CCS) sector, for the reduction of the $\mathrm{CO}_{2}$ emissions to the atmosphere [3,4], and in the thermochemical energy storage (TCES) in concentrated solar power (CSP) plants [5-8].

In regards to the CCS, different separation techniques are available to separate the $\mathrm{CO}_{2}$ from the combustion flue gases: absorption, adsorption, cryogenics separation, membranes, etc. [9-11]. Among these, amine-based absorption, even though being the most mature technological option [12,13], is characterized by several shortcomings, when applied for post-combustion capture: huge energy demand for the regeneration of the sorbent, ther$\mathrm{mal} / \mathrm{chemical}$ degradation of the amines, amine losses due to evaporation and corrosion problems [12]. Therefore, adsorption has been proposed as one of the most attractive and promising alternatives, being characterized by relatively low energy consumption for the sorbent regeneration, high selectivity, no liquid waste streams, and quite a wide range of possible operating temperatures [14-17]. In particular, regarding the critical issue of the sorbent regeneration [18-21], different strategies can be adopted, acting either on the 
pressure (PSA - pressure swing adsorption) or on the temperature (TSA-temperature swing adsorption) of the system to induce the desorption of the $\mathrm{CO}_{2}$ molecules [22-25]. In this framework, TSA combined with an indirect heating process (for example by means of heat exchanger tubes), is considered to be very promising for post-combustion operations $[21,24,26]$. However, the selection of the sorbent is crucial for adsorption to become a competitive solution [27-30]. Indeed, a good sorbent should be relatively convenient from the economic point of view, but, at the same time, it should be able to provide good performances at low $\mathrm{CO}_{2}$ pressure $(<0.2 \mathrm{~atm}$ [23]): high equilibrium adsorption capacity, fast kinetics of adsorption/desorption, stability to cyclic operations and tolerance to water vapor and other possible impurities in the exhaust stream [31]. In the framework of the need to produce specific adsorbent materials, fine/ultrafine particles have attracted growing interest in research [32]. Indeed, they can quite easily serve as the substrate for the production of ad-hoc synthesized sorbents, i.e., characterized by remarkable affinity towards the molecules of $\mathrm{CO}_{2}$ [27-29]. As a matter of fact, due to their distinctive properties, size, and nature their surface chemistry and porous structure can be easily adjusted/functionalized at the molecular level, i.e., by introducing chemical groups/ligands with basic functionalities (e.g., carbonates, amino groups, etc.) able to tailor their adsorption behavior towards the $\mathrm{CO}_{2}$ molecules [27-29,33-36]. Besides that, it must be considered that most of the sorbents commercially available are produced in a fine powdered form [27-29].

Likewise, fine/ultrafine powders have also been proposed as a possible solution to overcome the drawbacks of the calcium looping $(\mathrm{CaL})$ process, which can be carried out for both CCS [37] and TCES-CSP applications [7,8], according to the following reaction scheme:

$$
\mathrm{CaCO}_{3}(\mathrm{~s}) \rightleftarrows \mathrm{CaO}(\mathrm{s})+\mathrm{CO}_{2}(\mathrm{~g}) \Delta \mathrm{H}_{\mathrm{r}}^{0}=178 \mathrm{~kJ} / \mathrm{mol} .
$$

In the former case, $\mathrm{CaO} / \mathrm{CaCO}_{3}$ is used as sorbent material to capture/release $\mathrm{CO}_{2}$ by means of carbonation/calcination cycles [37]. In the latter case, $\mathrm{CaO}$ is used as an energy intensive material for the storage of energy in a chemical form by means of the reversible carbonation/calcination reaction $[7,8]$. In regards to the carbonation reaction, it must be underlined that it takes place in two successive stages: (i) a fast initial stage controlled by the reaction kinetics and by the transport of the $\mathrm{CO}_{2}$ molecules from the bulk phase to the particle surface and (ii) a slow final stage controlled by the diffusion of the $\mathrm{CO}_{2}$ molecules through the carbonate layer, which covers the remaining free surface of the $\mathrm{CaO}$ particles [38]. In light of this, it is clear that a poor gas-solid contact efficiency can strongly hinder the carbonation reaction [37]. Moreover, regardless of the specific application, i.e., either CCS or TCES, the main shortcoming of CaL is represented by the loss of $\mathrm{CaO}$ activity, i.e., the progressive drop of the carbonation conversion over repeated cycles due to sintering and pore-plugging $[39,40]$. Therefore, thanks to the extensive research effort devoted to finding solutions to this issue in the last years, different options are available to limit the natural $\mathrm{CaO}$ deactivation, such as: thermal activation [41,42], hydration [43], mechanical crushing [44,45], and the synthesis of Ca-based sorbents able to provide superior reactivity $[8,44,46]$. In this framework, the utilization of fine $\mathrm{CaO}$ particles has been recently proposed as a promising alternative solution [7,47]. In fact, it has been demonstrated that the sintering and pore-plugging phenomena can be remarkably hindered if $\mathrm{CaO}$ small particles are employed, thus improving the obtainable multicyclic performances [7,47]. Besides this, it has been reported that the use of fine $\mathrm{CaO}$ particles, thanks to their intrinsic high surface to volume ratio, makes it possible to enhance the gas-solid contact efficiency with respect to coarser $\mathrm{CaO}$ particles [37,48]. Likewise, the use, in small concentrations, of inert nano-sized particles as additives to fine cohesive limestone powders has been also proved to be a viable option to improve the flowability and reactivity performances of the system [49,50].

Therefore, in light of all the possible applications reviewed above, it is evident that it is necessary to develop new technologies to process these particles in big amounts. In this framework, several techniques can be used to handle and disperse fine/ultrafine powders in a continuous manner. Among these, fluidization is one of the most effective technological 
options. Indeed, fluidized beds can rely on different advantages, such as: high gas-solid contact area and efficiency, large heat/mass transfer coefficients, relatively easy control of the bed temperature uniformity, high particle flowability, flexibility in terms of types of powders to be processed, and suitability for large-scale applications [51].

However, regardless of these benefits of fluidized beds in handling powdered materials, it must be considered that fine/ultrafine particles, i.e., belonging to Geldart's $C$ group, cannot be fluidized under ordinary fluidization conditions due to their intrinsic cohesive nature $[1,2,52]$. Indeed, these particles are characterized by strong interparticle forces (IPFs), causing the natural formation of large aggregates, due to the particles tendency to stick to one another giving rise to larger structures as large as hundreds of microns $[1,2,53]$. This agglomeration tendency causes, in turn, channeling/plugging phenomena, thus hindering the possibility to obtain a proper fluidization quality under ordinary conditions $[2,53-56]$.

Therefore, fine/ultrafine powders can be fluidized only with the use of some kind of externally assisted fluidization devices, namely it is necessary to introduce some kind of external energy in order to overcome the strong inter-particle forces. Among the different alternatives (magnetic [57,58], electric fields [59,60], mechanical vibrations [61,62], etc.), sound-assisted fluidization has been proposed as one of the most effective solutions $[2,55,63]$. In particular, it has been reported that agglomeration, channeling and/or slugging phenomena can be efficiently hindered if a suitable acoustic field, i.e., capable of overcoming the IPFs, is applied, thus assuring the possibility to achieve a proper fluidization regime $[19,37,64,65]$.

In this context, the sound-assisted fluidized bed reactor (SAFB) designed and set-up in Naples by our research group has proven itself as a consistent device for the fundamental and phenomenological study of the fluidization behavior of the fine/ultrafine cohesive powders at atmospheric pressure $[2,54,55,66,67]$. More recently, the SAFB has also been upgraded to be used for both low- and high-temperature chemical processes, such as $\mathrm{CO}_{2}$ adsorption and Ca-looping, studied in the framework of both CCS and TCES-CSP applications [3-6,15,19-21,36,37,64,65,68,69].

In this work, the main results recently obtained by means of the SAFB setup are reviewed, particularly focusing on how the application of the acoustic perturbation reflects not only on the fluid dynamics of the system, but also on the performances/outcomes of the specific chemical processes carried out therein.

\section{Experimental Set-Up and Procedure}

\section{1. $S A F B$}

Figure 1 reports the scheme of the SAFB designed and set-up in Naples by our research group and used in all the works reviewed in the present manuscript. It is based on the initial setup originally conceived by Chirone et al. $[70,71]$ to study the fundamental behavior of cohesive powders at atmospheric pressure. The SAFB mainly consists of five parts: (i) the fluidization/reaction section; (ii) the acoustic section; (iii) the control section; (iv) the analysis section; and (v) acquisition section.

The fluidization section is made of a fluidization column in Plexiglas, Pyrex, or quartz, depending on the operating temperature. The column is provided with a gas distributor, consisting of a quartz porous plate. The section situated below the gas distributor is a wind-box. In particular, the proper gas distribution below the quartz plate is assured by a quartz rings filling. A pressure probe (linked to pressure transducers) located just above the gas distributor makes it possible to directly measure the pressure drops across the bed, i.e., without the contribution of the distributor plate.

The acoustic section consists of a sound-generation/propagation system. In particular, the acoustic field is generated by a digital signal generator, which is capable of generating an electrical sine wave of specified frequency (f). Then, the signal, amplified in a power audio amplifier rated up to $400 \mathrm{~W}$, is sent to an $8 \mathrm{~W}$ woofer loudspeaker and finally introduced in the fluidization column through a specifically designed sound wave guide, which is linked to the upper part of the fluidization column so that the sound wave 
propagates from the top to the bottom of the column. In particular, the geometry of this sound wave guide and, in turn, the reciprocal position of the loudspeaker and the fluidization column, have been properly conceived in order to protect the loudspeaker from any possible elutriated materials and/or from the heat emitted from the bed in the case of high temperature tests. The response of the bed to the acoustic perturbation is monitored through a microphone located in the upper part of the fluidization column and linked to an oscilloscope. This makes it possible to monitor and adjust the intensity (SPL) of the acoustic field according to the signal received from the bed through the microphone. Considering that the intensity of the acoustic fields generated in our research activity is relatively high $(>110 \mathrm{~dB})[3,54]$, the experimental set up envisages a noise insulation system based on the principles of the Helmholtz resonator [72-74]. The resonator simply consists of a cavity connected to the system of interest through one or several short and narrow tubes (necks). The resonator has a characteristic resonance frequency (to which corresponds the maximum oscillation), which is strictly dependent on its geometry, i.e., the volume of the cavity and the length of the neck [72-74]. Therefore, by properly selecting these geometrical parameters, it has been possible to make the resonance frequency characteristic of the resonator fall inside the frequency domain of interest, thus effectively dampening the noise [72-74].

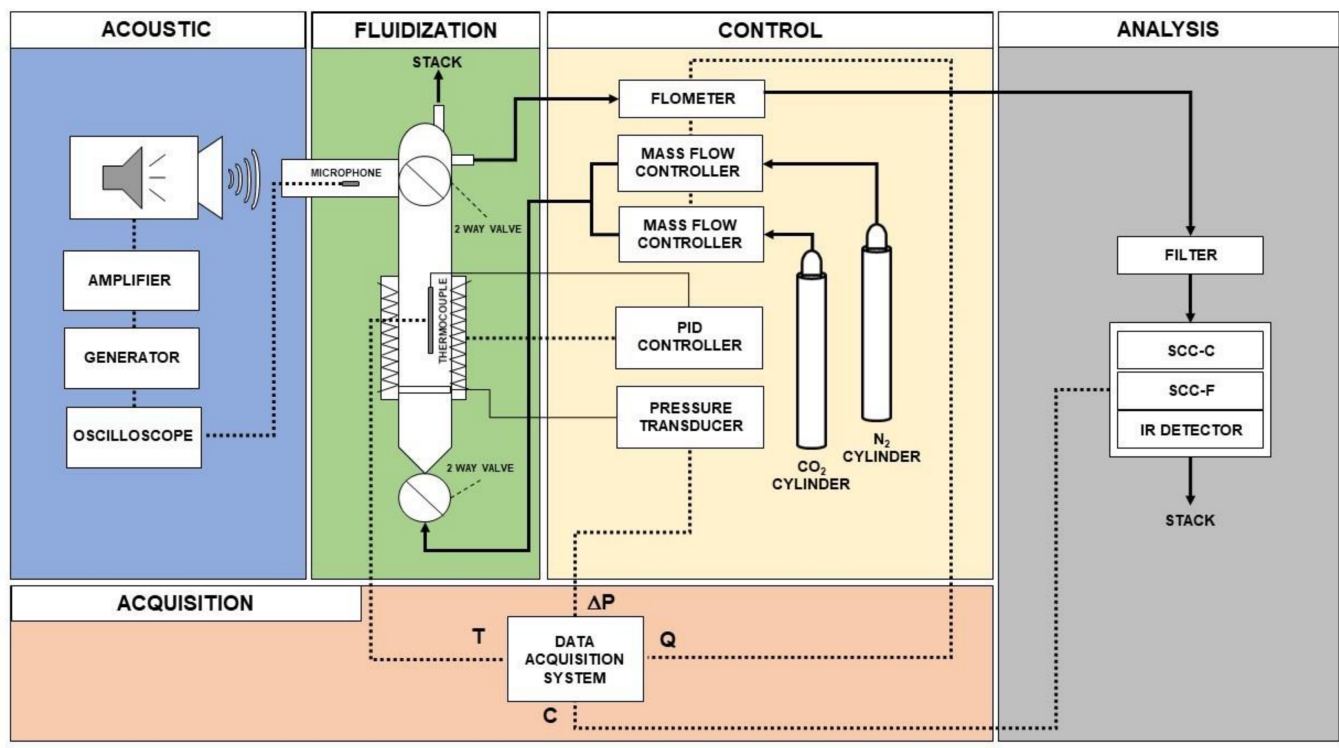

Figure 1. Sound-assisted fluidized bed reactor (SAFB): scheme of the experimental set-up.

The control section consists of all the devices used to set, measure, and control the operating variables of the experiments, i.e., the inlet gas flow rates and temperature. A set of mass flow meters and controllers (Brooks) with different full-scale values (ranging from 1 to $300 \mathrm{NL} \mathrm{h}^{-1}$ ) is used to set and control the inlet gas flow rate. Likewise, a mass flowmeter (Brooks) located at the exit of the column is used to measure the flow rate of outlet stream. The gas feed is prepared using separate high purity cylinders $(99.999 \%)$ containing the gaseous species $\left(\mathrm{N}_{2}\right.$ and $\left.\mathrm{CO}_{2}\right)$ required for the experiments. In regards to the temperature, it is set, measured, and controlled by a PID controller equipped with a type $\mathrm{K}$ thermocouple (positioned at the center of the bed), which is linked to an ad-hoc designed electric heating jacket (Tyco Thermal Controls $\mathrm{GmbH}$ ) specifically designed with an open window in order to visually assess the fluidization quality.

The analysis system is made of a continuous online analyzer (ABB, AO2020) with an infrared (URAS 14) detector (with a $0-100 \mathrm{CO}_{2}$ vol.\% full range) able to measure the outlet $\mathrm{CO}_{2}$ concentration continuously. In particular, a part of outlet stream is sampled by means of a sample gas feed unit (ABB, SCC-F) and sent to the analyzer, whereas the residual part is sent to the stack. The system is also equipped with a Peltier cooler (ABB, SCC-C) for 
cooling the sample and separating and removing any possible condensate. Besides that, the analysis system is also protected from any possible elutriated particles by a system of filters placed downstream from the exit of the fluidization column. With reference to the elutriation phenomena, it should be considered that under the application of acoustic fields, the elutriation of fine particles from the fluidized bed is remarkably reduced, thus limiting possible related issues such as clogging of valves [2].

Finally, in regards to the data acquisition system, the pressure drops $(\Delta \mathrm{P})$, temperature $(\mathrm{T})$, gas flowrate $(\mathrm{Q})$, and concentration $(\mathrm{C})$ signals are continuously recorded and elaborated on a PC, at a sampling rate of $1 \mathrm{~Hz}$, via LabView software.

\subsection{Materials}

All the materials tested in the SAFB are reported, with their main properties, in Table 1. Clearly, except for the silica sand, belonging to the Geldart's A group, all the powders are characterized by dimensions lower than $30 \mu \mathrm{m}$, i.e., they all belong to the Geldart's $C$ group. However, they can be categorized in two main groups on the basis of their primary particle size: nano-sized and micro-sized powders.

Table 1. Materials used in the SAFB.

\begin{tabular}{|c|c|c|c|c|c|c|c|c|}
\hline Dimension & Name & Primary Particle Size & $\begin{array}{c}D_{\text {sauter }} \\
(\mu \mathrm{m})\end{array}$ & $\begin{array}{c}\rho_{\mathrm{p}} \\
\left(\mathrm{kg} \mathrm{m}^{-3}\right)\end{array}$ & $\begin{array}{l}\text { BET SSA } \\
\left(\mathrm{m}^{2} \mathrm{~g}^{-1}\right)\end{array}$ & $\begin{array}{c}V_{p} \\
\left(\mathrm{~cm}^{3} \mathrm{~g}^{-1}\right)\end{array}$ & $\begin{array}{l}\text { m } \\
(g)\end{array}$ & Ref. \\
\hline \multirow{5}{*}{ 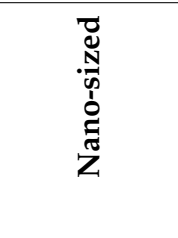 } & $\mathrm{Al}_{2} \mathrm{O}_{3}$ & $<50 \mathrm{~nm}$ & 2.02 & 4000 & - & - & 48 & {$[55,66,67]$} \\
\hline & $\mathrm{Fe}_{2} \mathrm{O}_{3}$ & $<50 \mathrm{~nm}$ & 0.43 & 4500 & - & - & 33 & {$[55,66,67]$} \\
\hline & $\mathrm{ZrO}_{2}$ & $<50 \mathrm{~nm}$ & & 6000 & - & - & 35 & [55] \\
\hline & $\mathrm{CuO}$ & $<50 \mathrm{~nm}$ & & 6300 & - & - & 75 & [55] \\
\hline & AC Norit & - & 0.39 & - & 1060 & 1.34 & 100 & $\begin{array}{c}{[3,4,15,19-} \\
21,37,55]\end{array}$ \\
\hline \multirow{6}{*}{ 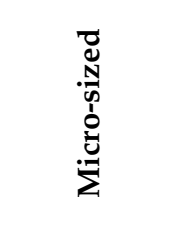 } & AC Sigma & - & 15.40 & - & 1038 & 1.14 & 100 & [3] \\
\hline & HKUST-1 & - & 4.30 & - & 680 & 0.66 & 50 & {$[3,68]$} \\
\hline & Ashes & $<60 \mu \mathrm{m}$ & 8.00 & 2000 & - & - & - & [54] \\
\hline & Silica sand & $<150 \mu \mathrm{m}$ & 60.00 & 2600 & - & - & - & [54] \\
\hline & Natural $\mathrm{CaCO}_{3}$ & - & 4.00 & - & 1.60 & - & 100 & {$[5,6]$} \\
\hline & * Synthetic CaO & - & $<100$ & - & & - & 100 & [37] \\
\hline
\end{tabular}

$\rho_{\mathrm{p}}=$ particle density; BET SSA = BET specific surface area; $\mathrm{V}_{\mathrm{p}}=$ pore volume; $\mathrm{m}=$ mass of powder loaded in the SAFB. * Tests performed in the Seville experimental apparatus.

In particular, the nano-powders are: $\mathrm{Al}_{2} \mathrm{O}_{3}, \mathrm{Fe}_{2} \mathrm{O}_{3}, \mathrm{ZrO}_{2}$, and $\mathrm{CuO}$, all of them produced by Sigma-Aldrich. Whereas, in regards to the micro-powders, the two commercial activated carbons are an activated carbon DARCO FGD (Norit), AC Norit, and an activated charcoal powder (Sigma Aldrich, Milan, Italy), AC Sigma. The metal organic framework (MOF), HKUST-1, has been synthesized according to the procedure reported in [68]. The natural limestone, $\mathrm{CaCO}_{3}$, comes from Belchite quarries (Spain) and has been supplied by OMYA. Finally, the synthetic $\mathrm{CaO}$ is produced by Sigma-Aldrich.

\subsection{Fluidization Tests}

All the fluidization experiments have been carried out in the SAFB at atmospheric pressure and at temperatures ranging from 25 to $850^{\circ} \mathrm{C}$ under ordinary ad sound-assisted operating conditions. The fluidizing gas is $\mathrm{N}_{2}$ in order to avoid air moisture that could intensify the powder cohesiveness. In regards to the sound-assisted tests, acoustic fields with different sound frequency (f: $20-300 \mathrm{~Hz}$ ) and intensity (SPL: 120-150 dB) have been applied in order to study the effect of the acoustic parameters on the fluidization behavior.

Each fluidization experiment consists in measuring and recording the pressure drops as a function of the superficial gas velocity $(\mathrm{u})$, i.e., by both decreasing (DOWN) and increasing (UP) $\mathrm{u}$. All of the results shown in this work have been obtained from the DOWN curves. Then, the main fluidization parameters are evaluated by working out 
to the obtained experimental data, i.e., the minimum fluidization velocity $\left(\mathrm{u}_{\mathrm{mf}}\right)$ and the average aggregate size $\left(\mathrm{d}_{\mathrm{agg}}\right)$.

In regards to $\mathrm{u}_{\mathrm{mf}}$, the well-known graphical procedure is applied to the experimental pressure drop curve: $\mathrm{u}_{\mathrm{mf}}$ is evaluated by crossing the line that fits the data for flow through a packed bed and the horizontal line that fits the data for the fully fluidized bed [75].

In regards to $d_{a g g}$, the correlation proposed by Wen and $Y u$ [75] has been applied using the experimental values of $u_{\mathrm{mf}}$. In particular, an apparent density, smaller than the primary particle density, has been considered for the aggregates [54].

\section{4. $\mathrm{CO}_{2}$ Adsorption Tests}

Dynamic adsorption/desorption experiments have been carried out in the SAFB under atmospheric pressure and different adsorption/desorption temperatures $\left(\mathrm{T}_{\mathrm{ads}}, \mathrm{T}_{\mathrm{des}}\right)$ ranging from 25 to $150{ }^{\circ} \mathrm{C}$ and either with or without the assistance of the sound perturbation. In particular, relatively low values of $\mathrm{CO}_{2}$ partial pressures $\left(\mathrm{P}_{\mathrm{CO}_{2}}: 0.05-0.20 \mathrm{~atm}\right)$ have been tested in order to simulate the composition of a typical post-combustion flue gas. The feeding stream in both the adsorption and desorption step is set so that superficial gas velocity is sufficiently bigger than the $\mathrm{u}_{\mathrm{mf}}$ of the tested sorbent, thus assuring that the whole bed is fully fluidized.

In particular, cyclic tests of $\mathrm{CO}_{2}$ capture and recovery have been performed according to the TSA approach. Therefore, each cycle consists of an adsorption step, in which the $\mathrm{CO}_{2}$ is captured on the solid sorbent, and a subsequent desorption step, in which the sorbent is regenerated by increasing the temperature of the system and the $\mathrm{CO}_{2}$, previously captured, is released.

Adsorption: Before the adsorption test, a preliminary step is always performed: the sorbent is firstly dried/cleaned by flowing $\mathrm{N}_{2}$ at $150{ }^{\circ} \mathrm{C}$ and atmospheric pressure for $60 \mathrm{~min}$ (this is necessary to remove any trace of water, which would end up reducing the $\mathrm{CO}_{2}$ adsorption capacity). Then, it is pre-conditioned by fluxing $\mathrm{N}_{2}$ through the system until the system reaches the desired temperature. After this preliminary stage, the adsorption step is started, in which the feed to the column is switched to a $\mathrm{CO}_{2} / \mathrm{N}_{2}$ gas mixture of specified composition $\left(\mathrm{C}_{0}\right)$. Thanks to the continuous monitoring of the $\mathrm{CO}_{2}$ concentration in the outlet stream, the breakthrough (BT) curves, consisting in the plot of $\mathrm{C} / \mathrm{C}_{0}$ versus time, are obtained. Then, the BT curves are elaborated in order to calculate some important adsorption parameters:

- $\mathrm{q}_{\mathrm{e}}$ - the amount of $\mathrm{CO}_{2}$ adsorbed per unit mass of adsorbent at the thermodynamic equilibrium. In particular, this is evaluated from the integration of the BT curve according to the following mass balance:

$$
\mathrm{q}_{\mathrm{e}}=\frac{1}{\mathrm{~m}} \int_{0}^{\mathrm{t}_{\mathrm{s}}}\left(\mathrm{F}_{\mathrm{CO}_{2}, \text { in }}-\mathrm{F}_{\mathrm{CO}_{2}, \text { out }}\right) \mathrm{dt}
$$

where $\mathrm{m}$ is the sorbent mass, $\mathrm{F}_{\mathrm{CO}_{2} \text {, in }}$ and $\mathrm{F}_{\mathrm{CO}_{2} \text {, out }}$ are the inlet and outlet $\mathrm{CO}_{2}$ molar flowrate, respectively, and $t_{s}$ is the saturation time;

- $t_{b}$-the BT time, namely, the time in which the outlet $\mathrm{CO}_{2}$ concentration is the $5 \%$ of the feed concentration. Technically, in real industrial adsorption processes, it is the time at which the adsorber is taken off-line for regenerating the sorbent, which means that larger values of $t_{b}$ correspond to the more effective capture capacities;

- $\Delta \tau-$ a time parameter providing information on the kinetics of the adsorption process. The smaller $\Delta \tau$ is, the faster the adsorption will be. In particular, it is representative of the slope of the linear part of the BT curve and it is evaluated as $t_{95}-t_{b}$ (with $t_{95}$ being the time for which the outlet $\mathrm{CO}_{2}$ concentration reach $95 \%$ of the concentration in the feed), which means that higher values of $\Delta \tau$ represents steeper BT curves;

- $\psi$-the fraction of bed used at BT, namely the percentage of the total captured $\mathrm{CO}_{2}$ $\left(\mathrm{q}_{\mathrm{e}}\right)$ which is adsorbed at the BT time, $\mathrm{t}_{\mathrm{b}}$.

Desorption: In regards to the desorption step, different regeneration modes have been used: 
- non-isothermal purge-in this mode of operation, the heating happens contextually to the $\mathrm{N}_{2}$ purging step. In particular, once the adsorption step is concluded, the column is heated up $\left(20^{\circ} \mathrm{C} / \mathrm{min}\right)$ to the selected $\mathrm{T}_{\text {des }}$ and, at the same time, the feed (QIN) is switched from the $\mathrm{CO}_{2} / \mathrm{N}_{2}$ mixture, used during the previous adsorption step, to pure $\mathrm{N}_{2}\left(\mathrm{Q}_{\mathrm{p}}\right)$ to purge the bed.

- isothermal purge-in this mode of operation, the purging step happens isothermally. In particular, once the adsorption step is concluded, the column is isolated so that all the desorbed $\mathrm{CO}_{2}$ is kept inside the column. To do so, the inlet and outlet of the column are closed by means of two-way valves and, in the case of sound-assisted adsorption tests, the acoustic field is switched off and the system is heated up to the selected desorption temperature. Then, once the set $T_{\text {des }}$ is reached, the purging step is started, namely, the acoustic field is switched on, in the case of sound-assisted tests, the feed to the column is opened fluxing $\mathrm{N}_{2}$ and the column exit is un-sealed. In this way, the $\mathrm{CO}_{2}$ already desorbed from the adsorbent, which has been trapped inside the isolated column, and the $\mathrm{CO}_{2}$ still adsorbed on the sorbent (i.e., the $\mathrm{CO}_{2}$ that can be released only by reducing the $\mathrm{CO}_{2}$ partial pressure) exits from the column diluted in the $\mathrm{N}_{2}$ stream.

In analogy to the adsorption step, thanks to the continuous monitoring of the $\mathrm{CO}_{2}$ concentration in the outlet stream, the desorption peaks are elaborated in order to calculate some important desorption parameters:

- $\mathrm{R}$-the $\mathrm{CO}_{2}$ recovery level, defined as the percentage of the previously captured $\mathrm{CO}_{2}$ which is recovered during the desorption step;

- $\quad t_{d}$-the time needed for $\mathrm{CO}_{2}$ desorption at a fixed value of $\mathrm{R}$;

- $\mathrm{C}_{\mathrm{m}}-\mathrm{CO}_{2}$ purity, expressed as the average $\mathrm{CO}_{2}$ concentration in the desorbed stream.

\subsection{Ca-Looping Tests}

CaL tests have been performed for both CCS and TCES applications either with or without the assistance of the acoustic perturbation. However, only the tests for TCES have been performed in the SAFB in Naples, whereas those for CCS have been performed in the experimental apparatus set up in Seville in collaboration with the University of Seville. Detailed information on this experimental apparatus can be found in [37].

The experimental procedures used for both the CCS and TCES are similar, they only differ for the operating temperatures of the carbonation and calcination steps. In fact, the optimal operating conditions to perform the CaL process are strictly dependent on the particular application. In the case of CCS applications: the calcination, whose conditions are dictated by the need of extracting from the calciner high-concentration $\mathrm{CO}_{2}$ stream to be compressed and sequestered, is performed at high temperature $\left(\sim 950^{\circ} \mathrm{C}\right)$ under high $\mathrm{CO}_{2}$ partial pressure. The carbonation, whose conditions are dictated by the fixed concentration of the combustion flue gases, is performed under low $\mathrm{CO}_{2}$ partial pressure $(\sim 0.15$ bar $)$ at the lowest possible temperature $\left(\sim 650^{\circ} \mathrm{C}\right)$ able to favor the reaction thermodynamically [5]. In the case of TCES applications: since there is no more $\mathrm{CO}_{2}$ capture/storage issue, relatively low temperatures $\left(\sim 750{ }^{\circ} \mathrm{C}\right)$ and $\mathrm{CO}_{2}$ partial pressures (i.e., by using a gas easily separable from $\mathrm{CO}_{2}$, such as superheated steam or helium) are employed to perform the calcination. On the contrary, aiming at achieving high global efficiency for energy storage and electricity generation, high $\mathrm{CO}_{2}$ partial pressures and temperatures (around or above $800{ }^{\circ} \mathrm{C}$ ) are employed to perform the carbonation [5].

In both cases, CCS and TCES tests, the sorbent is subjected to a sound-assisted (150 dB$120 \mathrm{~Hz}$ ) pre-treatment step, in which it is pre-calcined in $\mathrm{N}_{2}$ at $900{ }^{\circ} \mathrm{C}$ in order to obtain a completely de-carbonated sorbent for the following carbonation step.

CCS: After the pretreatment, the sorbent is subjected to a carbonation step, performed at $650{ }^{\circ} \mathrm{C}$ feeding a mixture of $15 \% \mathrm{CO}_{2} / 85 \% \mathrm{~N}_{2} v / v$ until the saturation of the sorbent. Then, a calcination step is performed at $900{ }^{\circ} \mathrm{C}$ in $\mathrm{N}_{2}$ atmosphere to fully de-carbonate the sorbent. 
TCES: The operating conditions have been carefully chosen in order to simulate a CaL-CSP integration scheme in which the calcination is carried out at low temperature feeding helium and the carbonator is integrated with a closed $\mathrm{CO}_{2}$ Brayton cycle [76]. In particular, after the pre-treatment, the sorbent is subjected to a carbonation step carried out at $850{ }^{\circ} \mathrm{C}$ using a mixture of $70 \% \mathrm{CO}_{2} / 30 \% \mathrm{~N}_{2} v / v$ until the sorbent is saturated. Then, a calcination step is performed at $750{ }^{\circ} \mathrm{C}$ in $\mathrm{N}_{2}$ atmosphere until the sorbent is completely de-carbonated.

Also for these tests, the outlet $\mathrm{CO}_{2}$ concentration profiles are elaborated in order to calculate the carbonation conversion, $\mathrm{X}$.

\section{Results}

In the following paragraphs, the main results obtained by means of the SAFB setup are presented and reviewed, pointing out how the application of the acoustic perturbation affects the fluid dynamics of the system and, in turn, also the performances/outcomes of the specific chemical processes carried out therein.

\subsection{Fluid Dynamics of Sound-Assisted Fluidized Beds}

Studying the behavior of different fine/ultrafine cohesive particles, it has been shown that, regardless of the specific particle size, the application of an acoustic perturbation, with proper $\mathrm{f}$ and SPL, makes it possible to either achieve an appropriate fluidization regime or improve their fluidization quality $[2,55]$, in terms of ideal-like pressure drop curves and affecting the values of all the most important fluidization parameters (lower values of $\mathrm{u}_{\mathrm{mf}}$ and $\mathrm{d}_{\mathrm{agg}}$ ). In this framework, Figures 2 and 3 report, as examples, the fluidization and expansion curves obtained for different nano-sized and micro-sized powder, respectively, under ordinary and sound-assisted conditions.
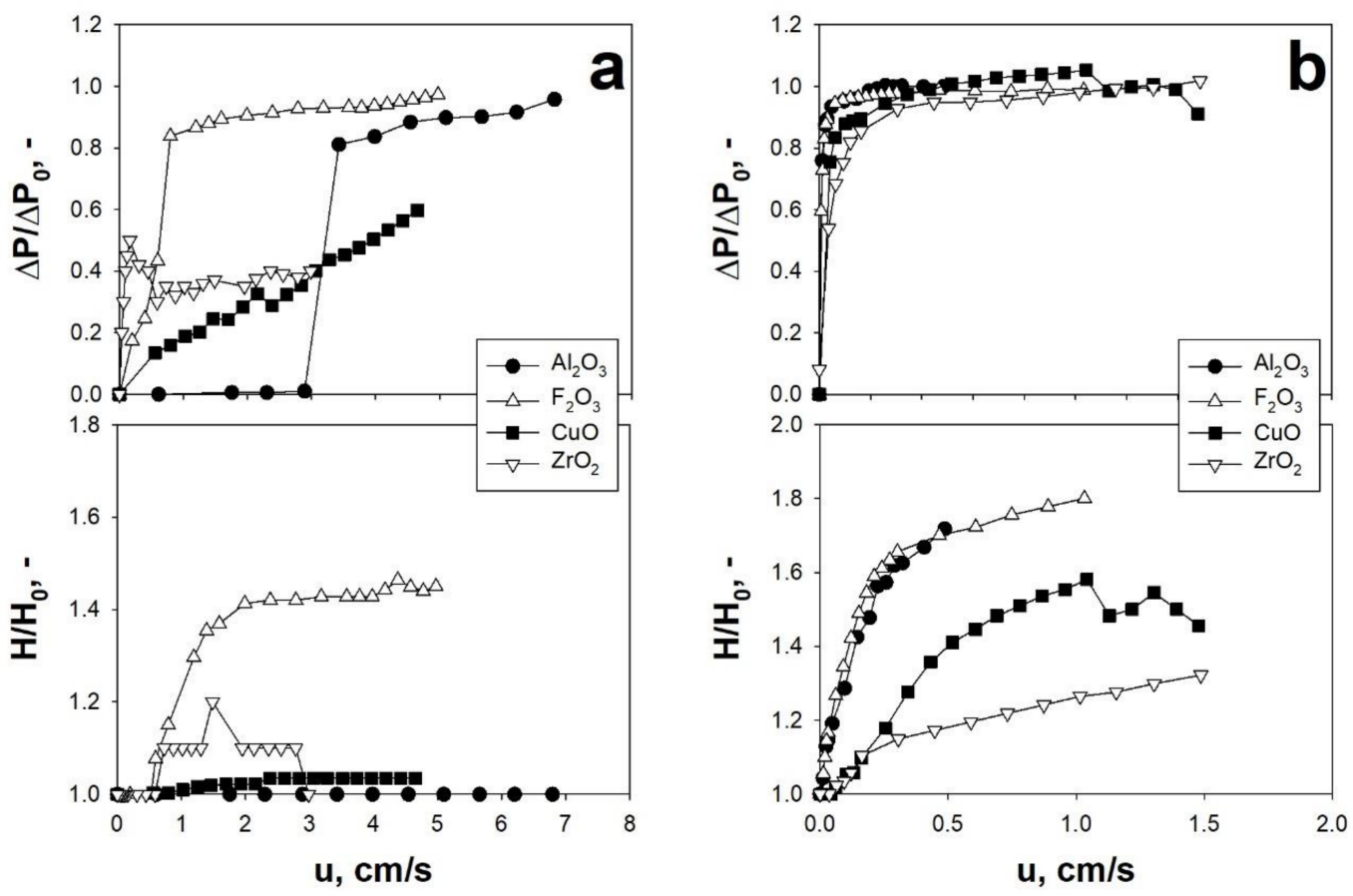

Figure 2. Dimensionless pressure drop $\left(\Delta \mathrm{P} / \Delta \mathrm{P}_{0}\right)$ and bed expansion $\left(\mathrm{H} / \mathrm{H}_{0}\right)$ curves obtained for different nano-sized particles: (a) ordinary tests; (b) sound-assisted tests (140 dB-120 Hz). $\mathrm{T}=$ ambient temperature. Adapted from [55] with permission. 

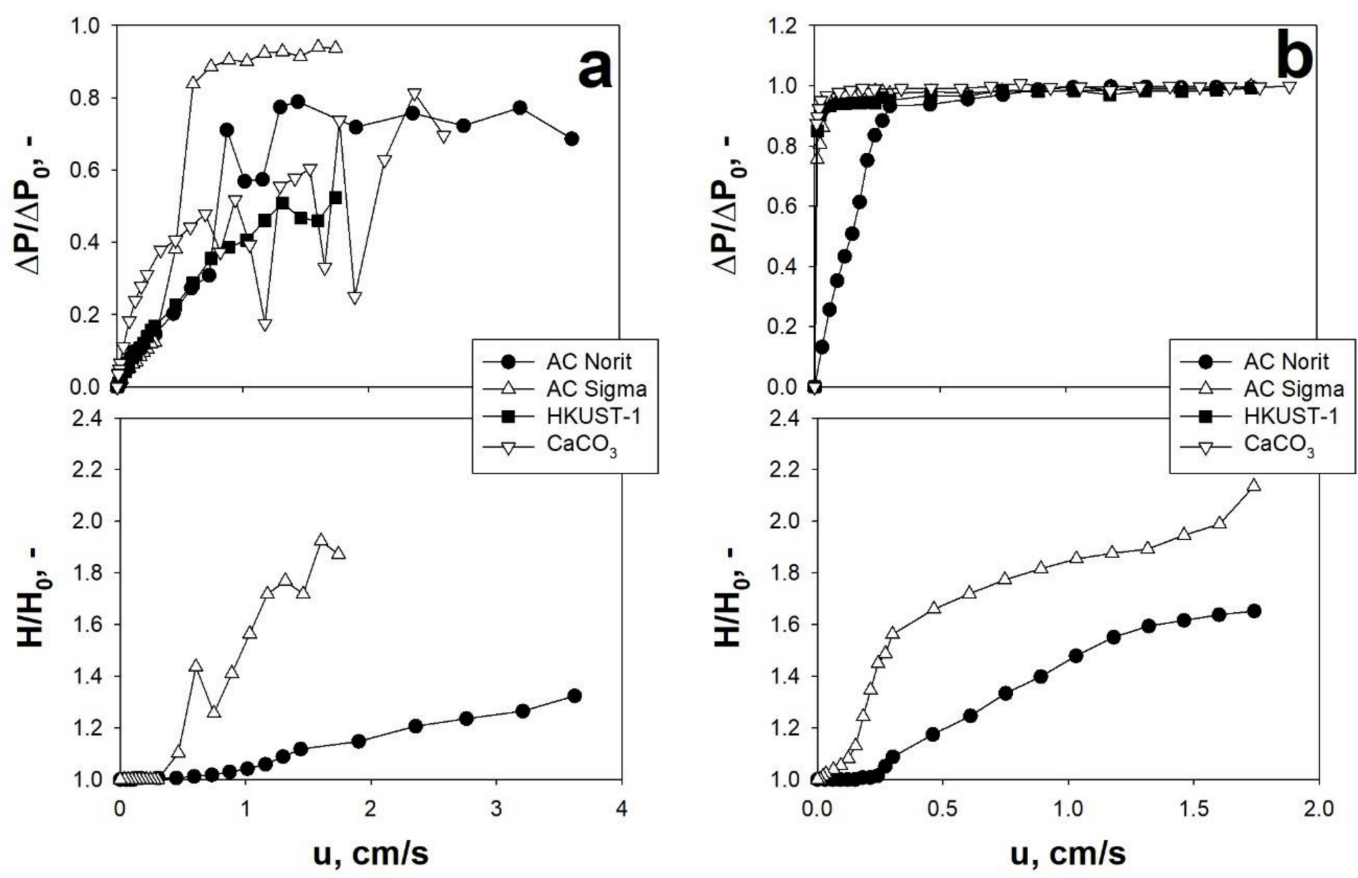

Figure 3. Dimensionless pressure drop $\left(\Delta \mathrm{P} / \Delta \mathrm{P}_{0}\right)$ and bed expansion $\left(\mathrm{H} / \mathrm{H}_{0}\right)$ curves obtained for different micro-sized particles: (a) ordinary tests; (b) sound-assisted tests (AC Norti/AC Sigma/HUST-1: $140 \mathrm{~dB}-80 \mathrm{~Hz} ; \mathrm{CaCO}_{3}: 150 \mathrm{~dB}-120 \mathrm{~Hz}$ ). T = ambient temperature. Adapted from [3,5] with permission.

Clearly, from the analysis of Figures $2 a$ and $3 a$, it is evident that when the powders are fluidized without any external excitation, the fluidization quality is relatively poor, as confirmed by the dimensional pressure drops being unstable and lower than 1 , which means that a fraction of the bed remains not fluidized. On the contrary, when the acoustic perturbation is applied, the fluidization curves become more regular, with the whole bed fluidized $\left(\Delta \mathrm{P} / \Delta \mathrm{P}_{0}\right.$ always reaching 1$)$ and higher values of expansion ratio (Figures $2 \mathrm{~b}$ and $3 \mathrm{~b}$ ). These experimental evidences are due to the fact that the application of a proper sound excitation is able to overcome the strong interparticle forces, thus hindering the agglomeration, channeling, and/or slugging phenomena. More specifically, the application of the acoustic perturbation generates both inertia and viscous forces that induce an oscillatory motion of gas molecules and solid particle/aggregates. In particular, depending on the dimension of the fluidizing aggregates (i.e., cluster and sub-clusters), the entity of this motion can be more or less intense [53]. This results in a relative motion between particle aggregates of different dimensions, which, in turn, induces a dynamic break-up mechanism of the bigger clusters into smaller and more easily fluidizable sub-clusters, as theoretically explained in [54].

The dynamics of the break-up mechanism has been also clearly highlighted investigating the mixing of different nano-sized powders $\left(\mathrm{F}_{2} \mathrm{O}_{3}\right.$ and $\left.\mathrm{Al}_{2} \mathrm{O}_{3}\right)$. In particular, combining the color tracing method with SEM/EDS morphological/chemical analysis of samples taken from the bed at different times, it has been demonstrated that the acoustic perturbation promotes a dynamic evolution of the fluidizing aggregates. In fact, the fluidizing aggregates, initially formed by only one of the two powders, are not static but dynamic structures, as confirmed by the fact that their chemical composition varies with time during the sound-assisted mixing test. Due to the aggregates continuously breaking-up and re-aggregating, there is an actual exchange of material at the micron scale which creates hybrid aggregates containing both of the two types of particles. More specifically, while the bed appears macroscopically well mixed after just few minutes, the local mixing inside the aggregates takes longer times. These considerations are clearly evidenced in Figure $4 \mathrm{a}, \mathrm{b}$ reporting, respectively, the chemical composition of the hybrids aggregates and the time evolution of the mixing degree $M$, where $M(t)$ is the ratio between the number of aggregates 
having a chemical composition different from the theoretical value of less than $10 \%$ and the total number of aggregates analyzed at the time $t$ [66].
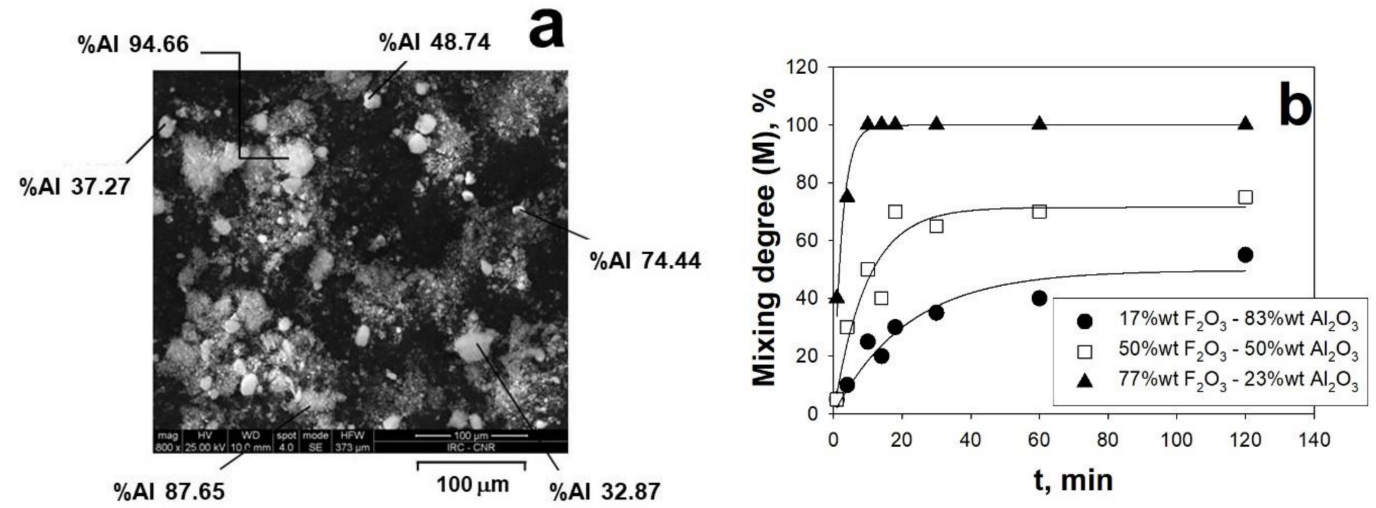

Figure 4. (a) SEM images and EDS analysis of the fluidizing aggregates taken from the bed after 14 min during the sound-assisted mixing test ( 17 wt. $\% \mathrm{~F}_{2} \mathrm{O}_{3}-83$ wt.\% $\left.\mathrm{Al}_{2} \mathrm{O}_{3}\right) ;(\mathbf{b})$ time evolution of the aggregates mixing degree for different relative amounts of the two nano-powders. $\mathrm{T}=$ ambient temperature. Adapted from [66] with permission.

\subsubsection{Effect of Sound Intensity and Frequency}

Aiming at highlighting the effect of the acoustic parameters, i.e., SPL and $\mathrm{f}$, on the fluidization behavior of fine/ultrafine particles, tests have been performed in the SAFB applying acoustic fields of different SPL (120-150 dB) and f (20-300 Hz). In this framework, Figure $5 \mathrm{a}, \mathrm{b}$ report the effect of SPL and $\mathrm{f}$ on the fluidization behavior, in terms of $\mathrm{u}_{\mathrm{mf}}$, of different nano-sized and micro-sized particles, respectively.
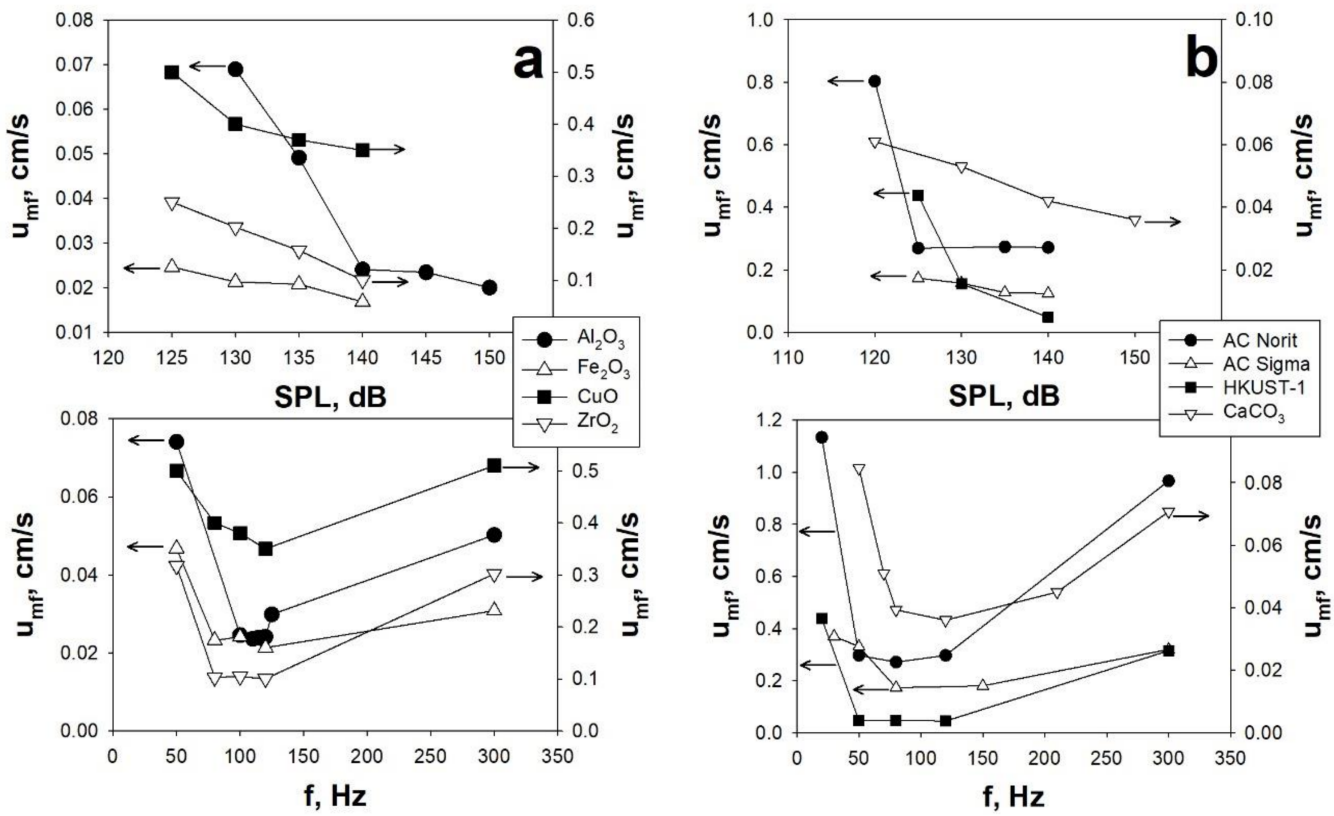

Figure 5. $\mathrm{u}_{\mathrm{mf}}$ as a function of SPL, at fixed frequency, and frequency, at fixed SPL, for: (a) nano-sized particles (fixed $\mathrm{f}=120 \mathrm{~Hz}$; fixed SPL $=140 \mathrm{~dB}$ ); (b) micro-sized particles (AC Norti/AC Sigma/HUST1: fixed $\mathrm{f}=80 \mathrm{~Hz}$, fixed $\mathrm{SPL}=140 \mathrm{~dB} ; \mathrm{CaCO}_{3}$ : fixed $\mathrm{f}=120 \mathrm{~Hz}$, fixed $\mathrm{SPL}=150 \mathrm{~dB}$ ). $\mathrm{T}=$ ambient temperature. Adapted from $[3,5,55]$ with permission.

Clearly, in regards to the effect of SPL, it has been found that increasing intensities of the acoustic perturbation lead to a general enhancement of the fluidization quality (Figure 5). Indeed, the strength of the acoustic field is proportional to SPL [2,77] and, as a 
consequence, a minimum acoustic energy (SPL > $120 \mathrm{~dB}$ ) is required to start the break-up mechanism, which, in turn, promotes the fluidization process. Besides that, an increase of SPL results in enhancing the fluidization quality, as clearly confirmed by $\mathrm{u}_{\mathrm{mf}}$ decreasing with increasing SPL (Figure 5). Indeed, larger values of SPLs are representative of larger amount of external energy introduced inside the system, which means that the break-up mechanism is more effective, i.e., the larger fluidizing aggregates are disrupted in smaller and more fluidizable structures. However, it must be also considered that there is some experimental evidence that at very high values of SPL, this positive effect may be reversed because of the collision between particles and/or agglomerates becoming more and more probable, thus leading to an increase of the aggregate size [78].

On the contrary, in regards to the effect of sound frequency on the fluidization quality, it has been found that there is a non-monotonic correlation, indeed, it can be found an optimum range of frequency $(80-120 \mathrm{~Hz})$ in the proximity of to the natural frequency of the particle bed. This is clearly shown in Figure 5, where the existence of the optimum range of frequency, providing the lowest values of $\mathrm{u}_{\mathrm{mf}}$ (i.e., more efficient break-up mechanism), is evident for all the tested nano-sized and micro-sized powders. In regards to the explanation of this experimental evidence, it must be considered that for too small values of sound frequency, there is no relative motion between smaller and larger aggregates and, as a consequence, there is no aggregate break-up $[2,53,54]$. On the contrary, for too high, values of sound frequency, the propagation of the acoustic waves though the particulate bed cannot take place properly $[2,53,54]$. In fact, there is a proportional correlation between the sound absorption coefficient and the square of sound frequency [2,53,54]. Therefore, when the sound frequency is too high, the upper part of the bed absorbs most of the sound energy, whereas, the bottom of the bed is only interested by a weakened sound energy, thus meaning that the large aggregates located there are not efficiently disrupted $[2,53,54]$.

\subsubsection{Effect of Temperature}

It is generally accepted that the influence of the temperature on the fluidizing gas characteristics (density and viscosity) can be used to explain how the fluidization behavior is affected by the temperature only if the fluidization is controlled by the hydrodynamic forces (HDFs) [2,53,54,79-81]. On the contrary, other aspects must be taken into account if the IPFs are either comparable with or predominate over the HDFs, as typical in the fluidization of fine/ultrafine particles [53,54]. Indeed, the temperature affects as the gaseous phase, in terms of density and viscosity variations, as the solid phase, in terms of intensification of IPFs $[53,54]$. In this context, several authors studied the effect of the temperature on the fluidization behavior of different types of powders, reporting an increase of the IPFs with increasing values of the temperatures $[2,53,54,79,80]$. It has been also found that, in spite of the fluidization of coarser powders being generally controlled by HDFs and not affected by IPFS, non-cohesive A powders can switch to C-type fluidization behavior when the temperature is increased, as a consequence of the intensified IPFs outbalancing the HDFs [81].

The effect of the temperature on the fluidization behavior of $\mathrm{A}$ and $\mathrm{C}$ powders has been also investigated in the SAFB. According to this general consensus of the works available in the literature, it has been found that increasing temperatures negatively affect the fluidization quality due to the intensification of IPFs. Indeed, regardless of the powders being either $A$ or $C$ type, the fluidization parameters, $u_{m f}$ and $d_{a g g}$, are increased when the temperature is increased, as clearly shown in Figure 6. This can be explained considering that, as consequence of the intensified IPFs, the achievement of a fluidization regime becomes more and more difficult due to a less effective break-up mechanism. Indeed, with the intensification of IPFs the cohesive character of the powder is enhanced, i.e., with increasing temperatures, more and more particles adhere to one another to form larger aggregates (higher values of $\mathrm{d}_{\mathrm{agg}}$ ) (Figure $6 \mathrm{~b}$ ) which lead to larger values of $\mathrm{u}_{\mathrm{mf}}$ (Figure 6a). 

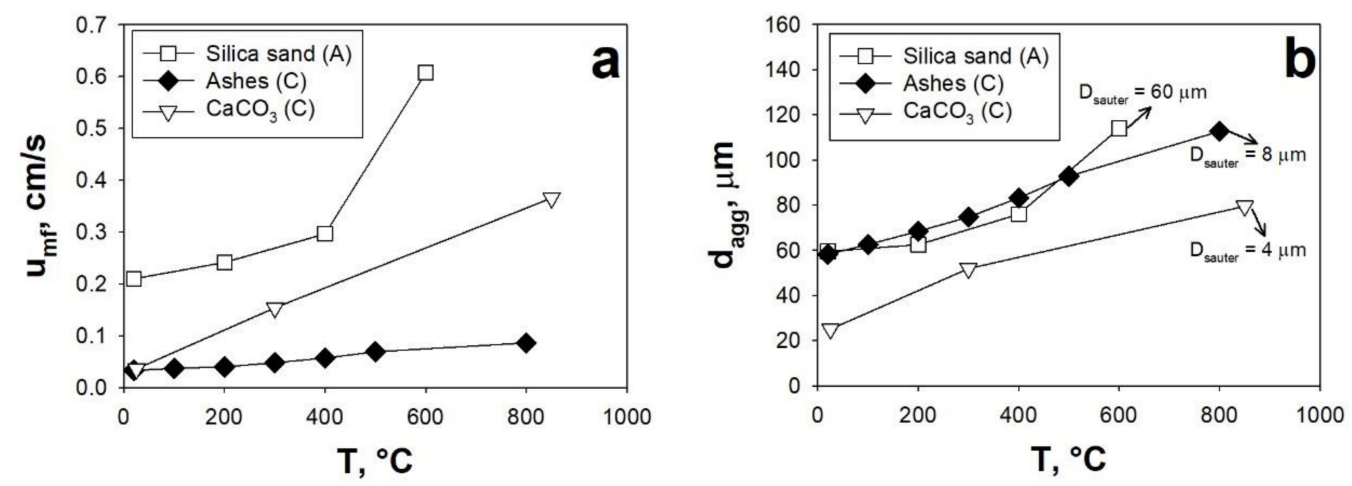

Figure 6. (a) $\mathrm{u}_{\mathrm{mf}}$ as a function of the temperature; (b) $\mathrm{d}_{\mathrm{agg}}$ as a function of the temperature. $\mathrm{SPL}=150 \mathrm{~dB} ; \mathrm{f}=120 \mathrm{~Hz} ; \mathrm{A}=$ powder belonging to the A group of Geldart's classification; $\mathrm{C}=$ powder belonging to the $C$ group of Geldart's classification. Adapted from $[5,54]$ with permission.

In particular, in regards to the $C$ type powders, it is clear that the efficiency of the acoustic perturbation decreases as the temperature is increased. In fact, as clearly inferable from Figure $6 b$, the fluidizing aggregate size, which is always larger than the powder average size (Ashes $=8 \mu \mathrm{m}, \mathrm{CaO}=4 \mu \mathrm{m}$-Table 1), increases more and more as the temperature is increased, becoming 13-15 times larger than the Sauter diameter around $800^{\circ} \mathrm{C}$.

Likewise, also in the case of the A type powder, increasing temperatures lead to a reduced efficiency of the acoustic field in counteracting the effect of IPFs. In fact, even though the fluidizing parameter increase whether or not the acoustic field is applied, the acoustic field keeps its effectiveness up to $200{ }^{\circ} \mathrm{C}$. In fact, the fluidizing aggregates are broken down to the Sauter diameter $(60 \mu \mathrm{m}$-Table 1$)$ only for temperatures smaller than $200{ }^{\circ} \mathrm{C}$, as confirmation of an effective break-up mechanism. On the contrary, when the temperature is increased beyond $200{ }^{\circ} \mathrm{C}$, the effectiveness of the acoustic field decrease until becoming negligible at $600{ }^{\circ} \mathrm{C}$, where no difference is observed between the ordinary and sound-assisted tests ( $d_{\text {agg }}$ is about two times the $D_{\text {sauter }}$ of the powder) (Figure $6 b$ ).

\subsection{Temperature Swing Adsorption (TSA)}

Since fine/ultrafine powders have great potential to be used for the $\mathrm{CO}_{2}$ adsorption process, the SAFB has been proposed in a TSA configuration (TSA-SAFB) as possible technology for the handling and processing of these materials in large quantities. In particular, an intense research activity has been performed to highlight and demonstrate that fine/ultrafine powdered sorbents, regardless of their specific chemical nature, can be directly used in the TSA-SAFB, i.e., they can be used as free-flowing powders, without being previously treated. In particular, there is no need to perform a previous pelletization step (which, on the contrary, would be necessary to face the huge pressure drops of fixed bed reactors of fine particles), which ends up in decreasing the sorbent surface area and, consequently, its adsorption capacity for $\mathrm{CO}_{2}$, especially for some kinds of novel cutting-edge sorbent materials [82]. Besides this crucial benefit, the TSA-SAFB has been also proved to significantly improve the $\mathrm{CO}_{2}$ adsorption and desorption performances of fine/ultrafine powdered sorbents with respect to their use in other standard reactor configurations (e.g., ordinary fluidized beds and fixed beds).

\subsubsection{Adsorption}

In regards to the adsorption step, Figure 7 reports the BT curves obtained for two adsorbents belonging to two different class of adsorbent materials, i.e., activated carbons and MOFs, under ordinary and sound-assisted fluidization conditions. Table 2 reports the adsorption parameters calculated from the elaboration of the BT curves. 

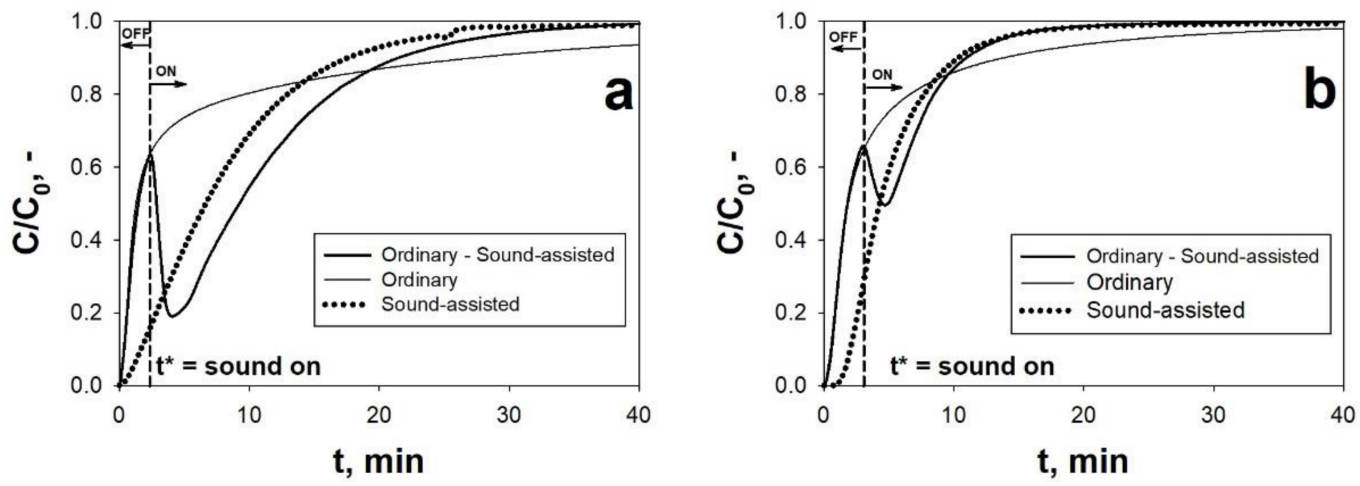

Figure 7. (a) $\mathrm{CO}_{2}$ breakthrough (BT) curves obtained for AC Norit during an ordinary fluidization test, a sound-assisted fluidization test and during a test in which the sound is switched on at $\mathrm{t}=\mathrm{t}^{*}$. $\mathrm{C}_{0}=10$ vol. $\% ; \mathrm{u}=1.5 \mathrm{~cm} / \mathrm{s} ; \mathrm{SPL}=140 \mathrm{~dB} ; \mathrm{f}=80 \mathrm{~Hz} ; \mathrm{T}=$ ambient temperature. $(\mathrm{b}) \mathrm{CO}_{2} \mathrm{BT}_{\text {curves }}$ obtained for HKUST-1 during an ordinary fluidization test, a sound-assisted fluidization test and during a test in which the sound is switched on at $\mathrm{t}=\mathrm{t}^{*} . \mathrm{C}_{0}=10 \mathrm{vol} . \% ; \mathrm{u}=1.5 \mathrm{~cm} / \mathrm{s} ; \mathrm{SPL}=140 \mathrm{~dB}$; $\mathrm{f}=120 \mathrm{~Hz} ; \mathrm{T}_{\mathrm{ads}}=$ ambient temperature. Adapted from $[37,68]$ with permission.

Table 2. Results of the ordinary and sound-assisted $\mathrm{CO}_{2}$ adsorption tests.

\begin{tabular}{|c|c|c|c|c|c|c|}
\hline \multirow[b]{2}{*}{ Type of Test } & \multicolumn{3}{|c|}{${ }^{1}$ AC Norit [4] } & \multicolumn{3}{|c|}{${ }^{2}$ HKUST-1 [68] } \\
\hline & $\begin{array}{c}\mathrm{q}_{\mathrm{e}} \\
\mathrm{mmol}^{-1} \mathrm{~g}^{-1}\end{array}$ & $\begin{array}{l}t_{b} \\
s\end{array}$ & $\begin{array}{l}\psi \\
-\end{array}$ & $\begin{array}{c}\mathrm{qe}_{\mathrm{e}} \\
\text { mmol g }^{-1}\end{array}$ & $\begin{array}{l}t_{b} \\
s\end{array}$ & $\begin{array}{l}\psi \\
-\end{array}$ \\
\hline Ordinary & 0.31 & 12 & 2.7 & 0.78 & 26 & 8 \\
\hline Sound-assisted1 & 0.37 & 63 & 15 & 1.14 & 141 & 29 \\
\hline
\end{tabular}

${ }^{1} \mathrm{SPL}=140 \mathrm{~dB} ; \mathrm{f}=80 \mathrm{~Hz} ; \mathrm{P}_{\mathrm{CO}_{2}}=0.10 \mathrm{~atm} ; \mathrm{u}=1.5 \mathrm{~cm} / \mathrm{s} ; \mathrm{T}_{\text {ads }}=$ ambient temperature. ${ }^{2} \mathrm{SPL}=140 \mathrm{~dB} ; \mathrm{f}=120 \mathrm{~Hz} ; \mathrm{P}_{\mathrm{CO}_{2}}=0.15 \mathrm{~atm} ;$ $\mathrm{u}=1.5 \mathrm{~cm} / \mathrm{s} ; \mathrm{T}_{\mathrm{ads}}=$ ambient temperature

The analysis of Figure 7 and Table 2 shows that the application of the acoustic perturbation remarkably improves the $\mathrm{CO}_{2}$ adsorption performances of both the two sorbents. Indeed, all the adsorption parameters of AC Norit and HKUST-1 are enhanced in the sound-assisted test with respect to the ordinary test: (i) the equilibrium adsorption capacity, $\mathrm{q}_{\mathrm{e}}$, is increased of about $20 \%$ and $45 \%$; (ii) the BT time, $\mathrm{t}_{\mathrm{b}}$, is increased of about 5 times; and (iii) the fraction of bed utilized at $t_{b}, \psi$, is increased of about 4 and 3 times for AC Norit and HKUST-1, respectively. Besides this, it is also evident that the adsorption kinetics is also enhanced when the system is assisted by the acoustic excitation, as clearly evidenced by the BT curves becoming steeper and shorter. Indeed, the saturation time, $t_{\mathrm{s}}$, is roughly reduced to a half and $\Delta \tau$ is reduced of about $60 \%$, thus meaning that the $\mathrm{CO}_{2}$ adsorption is speeded up when the acoustic perturbation is applied.

These experimental evidences can be explained considering that without the assistance of the acoustic perturbation, i.e., under ordinary conditions, the fluidization quality is extremely poor and characterized by strong instability. This is clearly evidenced by the fluidization curve obtained for both the sorbents (Figure 3a). Due to cohesive nature of the sorbents, the gas-solid contact efficiency is dramatically hindered and, therefore, most of the reactive gas $\left(\mathrm{CO}_{2}\right)$ bypasses the bed through the formation of channels rather than actually permeating the bed. Likewise, from the point of view of the solid phase, a great amount of the sorbent does not actually take part in the adsorption process, which means that a great amount of adsorbent surface is not exploited, being completely precluded to the gaseous phase. Then, once the most readily available adsorption sites (i.e., those located on the surface of the channels) are quickly saturated, the outlet $\mathrm{CO}_{2}$ concentration increases, due to the above-mentioned by-pass phenomenon, with a sudden increase of the slope of the BT curve. Then, after this sharp rise, the slope of the BT curve abruptly decreases approaching the saturation with a very slow tail of the BT curve, which accounts for most of the adsorption process. In particular, the saturation of the bed occurs very 
slowly due to the fact that only a small fraction of the solid and gaseous reactants takes part in the adsorption process.

On the contrary, when the acoustic perturbation is applied to the system, the BT curves show a more regular shape, i.e., with no sudden initial increase and slow tail, thanks to the enhanced of the fluidization quality and, in turn, of the gas-solid contact efficiency. More specifically, the general improvement of the $\mathrm{CO}_{2}$ adsorption performances observed during the sound-assisted tests is due to the characteristic dynamic break-up and re-aggregation mechanism of the fluidizing aggregates, as distinctive feature of the soundassisted fluidization process. In fact, this mechanism leads to the continuous renewing of the sorbent particles exposed to the fluid phase and, in turn, of the active sites available to the $\mathrm{CO}_{2}$ adsorption process.

This strong connection between the $\mathrm{CO}_{2}$ adsorption process and the sound-assisted fluidization process has been clearly evidenced by performing an OFF-ON test, in which the acoustic field is switched on only at a time $t=t^{*}$, i.e., soon after the above-discussed change of slope characteristic of the ordinary tests, (Figure 7). It is evident that when the acoustic perturbation is switched on, at $\mathrm{t}=\mathrm{t}^{*}$, the $\mathrm{CO}_{2}$ concentration profile suddenly decreases and, after few minutes, restart the rising with a sound-assisted-like shape. This experimental evidence is the confirmation that the acoustic perturbation makes it possible to better exploit the sorbent surface. In fact, the sorbent surface, that is precluded to the gaseous phase while the sound is switched off in the first part of the test, suddenly becomes available, as soon as the acoustic field is switched on. As a consequence, the $\mathrm{CO}_{2}$ concentration abruptly drops down, due to the renewed sorbent adsorption capacity.

The superiority of the SAFB reactor configuration to perform the $\mathrm{CO}_{2}$ adsorption process on fine/ultrafine sorbents have been also proved by testing the same sorbent (AC Norit) in a fixed bed reactor. In particular, the fixed bed experiments have been performed with the sorbent in both powdered and pelletized (pellet size: 180-400 $\mu \mathrm{m}$ ) form. The comparison of the obtained BT curves is reported in Figure 8. It is evident, in regards to the fixed bed tests, that the pelletization improves the performances with respect to the free-flowing powders. This is due to the fact of the strong cohesive nature of the fine sorbent, the gas flows through the bed through channels rather than permeating it. However, whether pelletized or not, when used in a standard fixed bed reactor, the sorbent provides remarkably worse $\mathrm{CO}_{2}$ adsorption performances than when used in the SAFB. In particular, in the SAFB, its adsorption capacity can be increased of about $76 \%$ with respect to the fixed bed operation with the pellets [4]. This is most likely due to diffusive resistances inside the pellets, hindering the full exploitation of the sorbent surface.

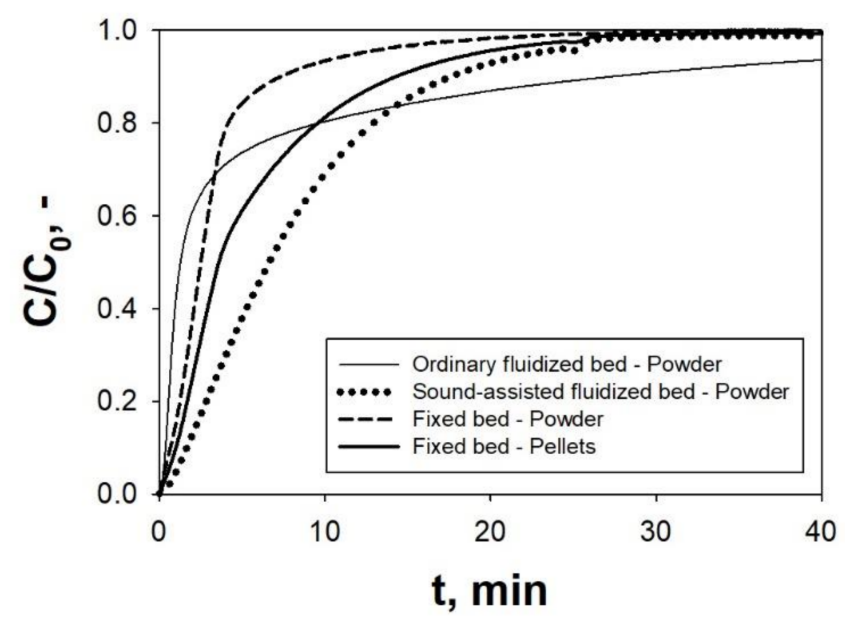

Figure 8. BT curves obtained under ordinary fluidization, sound-assisted fluidization and fixed bed conditions with AC Norit in powdered and pelletized form. $\mathrm{u}=1.5 \mathrm{~cm} / \mathrm{s} ; \mathrm{C}_{0}=10$ vol.\%; $\mathrm{SPL}=140 \mathrm{~dB} ; \mathrm{f}=120 \mathrm{~Hz} . \mathrm{T}_{\mathrm{ads}}=$ ambient temperature. Adapted from [37] with permission. 
The effect of some important operating variables on the $\mathrm{CO}_{2}$ adsorption process, i.e., $\mathrm{CO}_{2}$ partial pressure, $\mathrm{P}_{\mathrm{CO}_{2}}$, and temperature, $\mathrm{T}_{\mathrm{ads}}$, has also been investigated in the SAFB (Figure 9).
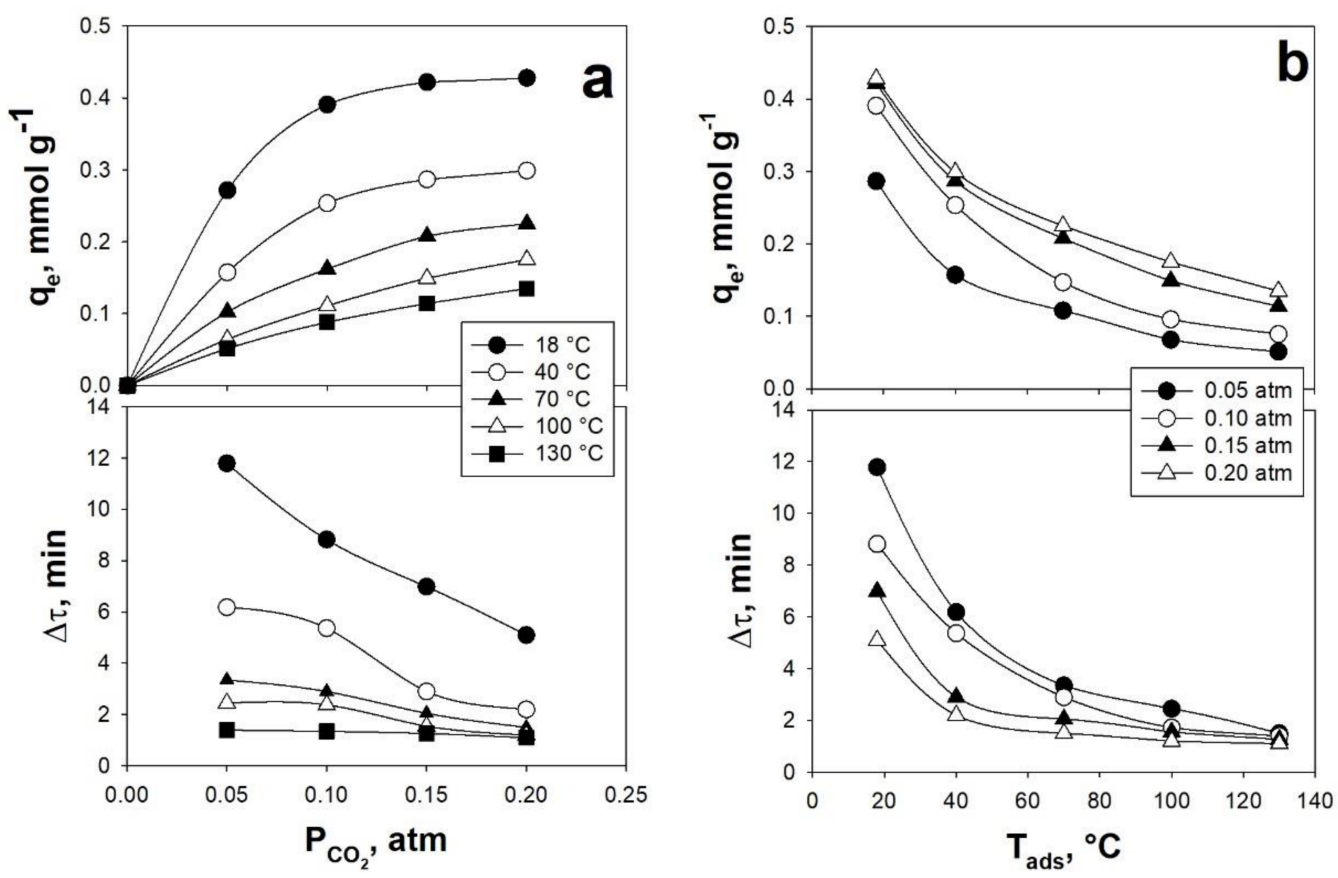

Figure 9. $\mathrm{q}_{\mathrm{e}}$ and $\Delta \tau$ obtained for $\mathrm{AC}$ Norit as functions of: (a) $\mathrm{P}_{\mathrm{CO}_{2}}$ at different values of $\mathrm{T}_{\mathrm{ads}}$ and (b) $\mathrm{T}_{\text {ads }}$ at different values of $\mathrm{P}_{\mathrm{CO}_{2}} \cdot \mathrm{u}=1.5 \mathrm{~cm} / \mathrm{s}$. Adapted from [69] with permission.

It is clear, from the analysis of Figure 9, that the pressure and the temperature have an effect on both the $\mathrm{CO}_{2}$ adsorption thermodynamics and kinetics.

In regards to the $\mathrm{CO}_{2}$ adsorption thermodynamics, it is positively affected by increasing values of $\mathrm{P}_{\mathrm{CO}_{2}}$, whereas, it is negatively affected by increasing values of $\mathrm{T}_{\text {ads }}$. Indeed, higher values of $\mathrm{P}_{\mathrm{CO}_{2}}$ lead to higher values of $\mathrm{q}_{\mathrm{e}}$, due to the fact that the $\mathrm{CO}_{2}$ adsorption process is thermodynamically controlled by $\mathrm{P}_{\mathrm{CO}_{2}}$ [17]. On the contrary, qe decreases with increasing $\mathrm{T}_{\mathrm{ads}}$, due to the adsorption being an exothermic process [11].

In regards to the $\mathrm{CO}_{2}$ adsorption kinetics, it is positively affected by increasing both $\mathrm{P}_{\mathrm{CO}_{2}}$ and $\mathrm{T}_{\mathrm{ads}}$. In fact, higher values of $\mathrm{P}_{\mathrm{CO}_{2}}$ lead to lower values of $\Delta t$, i.e., faster adsorption processes, due to the fact that longer times are needed by the $\mathrm{CO}_{2}$ concentration to go through the bed $[11,16]$. Likewise, larger values of $\mathrm{T}_{\text {ads }}$ also result in smaller values of $\Delta \mathrm{t}$, due to the enhancement of the mass-transfer coefficients at higher temperatures $[11,16]$.

\subsubsection{Desorption}

In regards to the desorption step, Figure 10a reports the desorption peaks and temperature profiles inside the bed obtained for the AC Norit under ordinary and sound-assisted fluidization conditions, using the non-isothermal purging mode described in the experimental section.

The analysis of Figure 10 evidences that, under both ordinary and sound-assisted fluidization conditions, the $\mathrm{CO}_{2}$ desorption profile shows the typical shape of a peak followed by a final tail, which is indicative of the $\mathrm{CO}_{2}$ desorption occurring slowly in the final stages due to the reduction of the driving force. Also, it is important to underline that, regardless of the fact that the process is carried out under sound-assisted or ordinary conditions, the sorbent is always fully regenerated, i.e., the desorbed $\mathrm{CO}_{2}$ is always the same as the $\mathrm{CO}_{2}$ previously adsorbed. However, even though the shapes of the ordinary and sound-assisted profile are similar, it is evident, in analogy to the results obtained for adsorption step, that the desorption profile is smoother and more regular under sound- 
assisted fluidization conditions. When no acoustic field is applied, on the contrary, a clear instability can be evidenced, which is caused by the fact that the establishment of preferential channels through the bed prevents a smooth desorption of the $\mathrm{CO}_{2}$. Besides this, the application of the sound also results in a faster heating rate, as clearly evidenced by the temperature profiles reported in Figure 10a, thanks to the larger heat transfer coefficients obtainable when the bed is fluidized, namely under sound-assisted conditions, with respect to those obtainable when the fluidization quality is poor, i.e., under ordinary conditions.
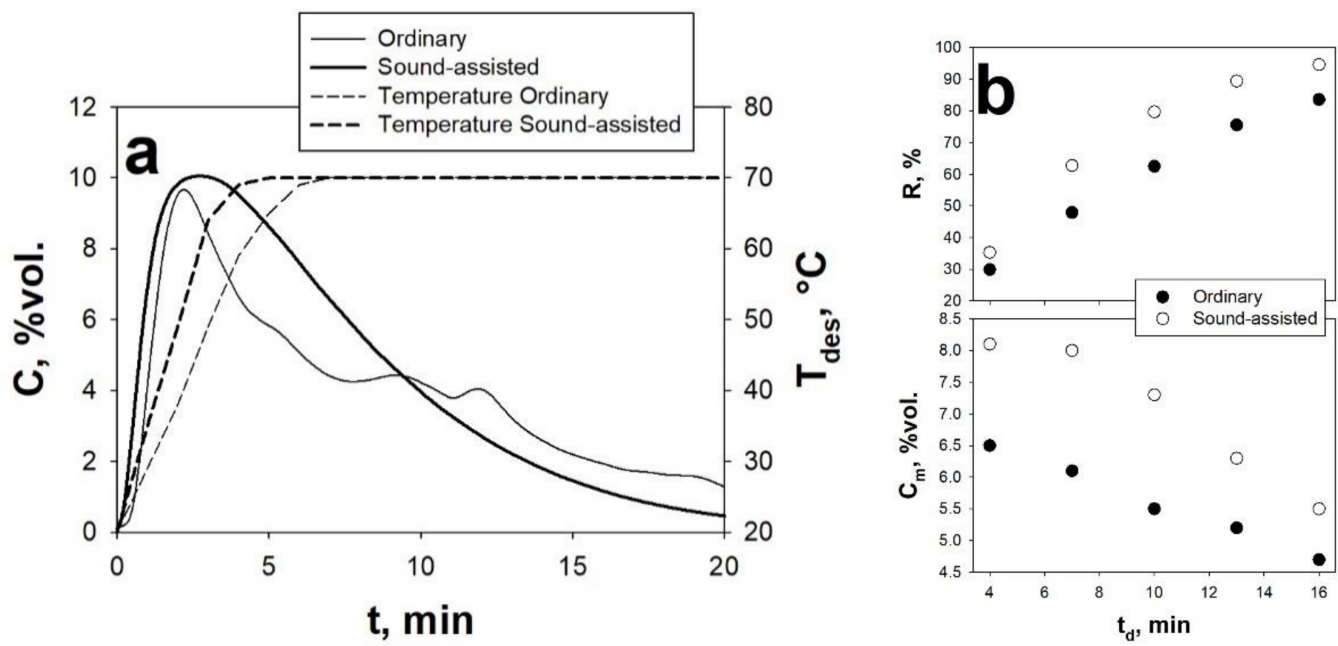

Figure 10. (a) Desorption peaks of the AC Norit obtained, using the non-isothermal purging mode, under ordinary and sound-assisted conditions. The sorbent temperature profile is also reported (dashed lines). $C_{0}=10$ vol. $\%$. (b) $R$ and $C_{m}$ as functions of $t_{d} \cdot Q_{p}=67.8 \mathrm{NL} \mathrm{h}^{-1}$; heating rate $=20^{\circ} \mathrm{C} / \mathrm{min}$ up to $\mathrm{T}_{\mathrm{des}}=70^{\circ} \mathrm{C}$. Adsorption step: ordinary fluidization; $\mathrm{Q}_{\mathrm{IN}}=67.8 \mathrm{NL} \mathrm{h}^{-1} ; \mathrm{C}_{0}=10 \mathrm{vol} . \%$ Adapted from [20] with permission.

The beneficial effect derived by the application of the sound is also highlighted by evaluating some important desorption parameters, namely the recovery level, $\mathrm{R}$, the desorption time at a fixed $R, t_{d}$, and the average $\mathrm{CO}_{2}$ concentration $\mathrm{C}_{\mathrm{m}}$. Clearly, as consequence of the peak-shaped desorption profile, whether the acoustic field is applied or not, higher $t_{d}$ values result in higher regeneration efficiency, i.e., larger values of R. However, at the same time, larger values of $t_{d}$ lead to lower values of $C_{m}$, due to the increasing dilution effect caused by prolonged $\mathrm{N}_{2}$ purging. This is evidently shown in Figure $10 \mathrm{~b}$, where it is clear that, when $t_{d}$ is increased, $R$ monotonically increases and $C_{m}$ monotonically decreases. It is also evident that, at each fixed value of $t_{d}$, both $R$ and $C_{m}$ are always larger in the sound-assisted test than in the ordinary test.

In analogy to the study performed on the $\mathrm{CO}_{2}$ adsorption step, the effect of some important operating variables on the $\mathrm{CO}_{2}$ desorption process, i.e., desorption temperature ( $\left.\mathrm{T}_{\text {des }}\right)$ and $\mathrm{N}_{2}$ purge flowrate $\left(\mathrm{Q}_{\mathrm{p}}\right)$, has been also investigated in the SAFB, using the isothermal purging mode described in Section 2.3. The results obtained are shown in Figures 11 and 12. First of all, it is important to highlight that, regardless of $T_{\text {des }}$ and $Q_{p}$, the sorbent can be fully regenerated $(R=100 \%)$, which agrees with the literature indicating the activated carbons as a physisorbent, i.e., the $\mathrm{CO}_{2}$ is adsorbed by the formation of weak physical bonds rather than strong chemical bonds on the sorbent surface $[15,18]$. 

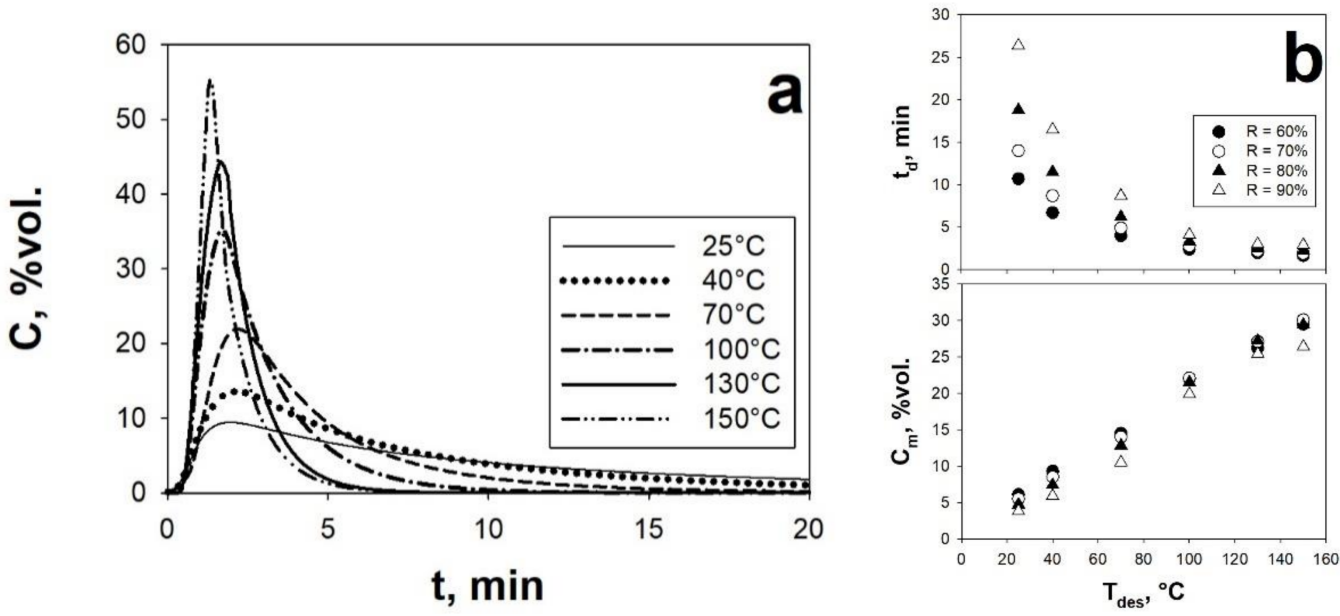

Figure 11. (a) Desorption peaks of AC Norit obtained, using the isothermal regeneration mode, under sound-assisted conditions at different $T_{\text {des }}$ at a fixed $Q_{p}\left(67.8 \mathrm{NL} \mathrm{h}^{-1}\right)$. (b) $t_{d}$ and $C_{m}$ as functions of the $T_{\text {des }}$ at fixed $Q_{p}\left(67.8 \mathrm{NL} \mathrm{h}^{-1}\right)$ and different values of $R$. Adsorption step: $S P L=140 \mathrm{~dB} ; \mathrm{f}=80 \mathrm{~Hz}$; $\mathrm{Q}_{\mathrm{IN}}=67.8 \mathrm{NL} \mathrm{h}^{-1} ; \mathrm{C}_{0}=10 \mathrm{vol} . \%$. Adapted from [19] with permission.
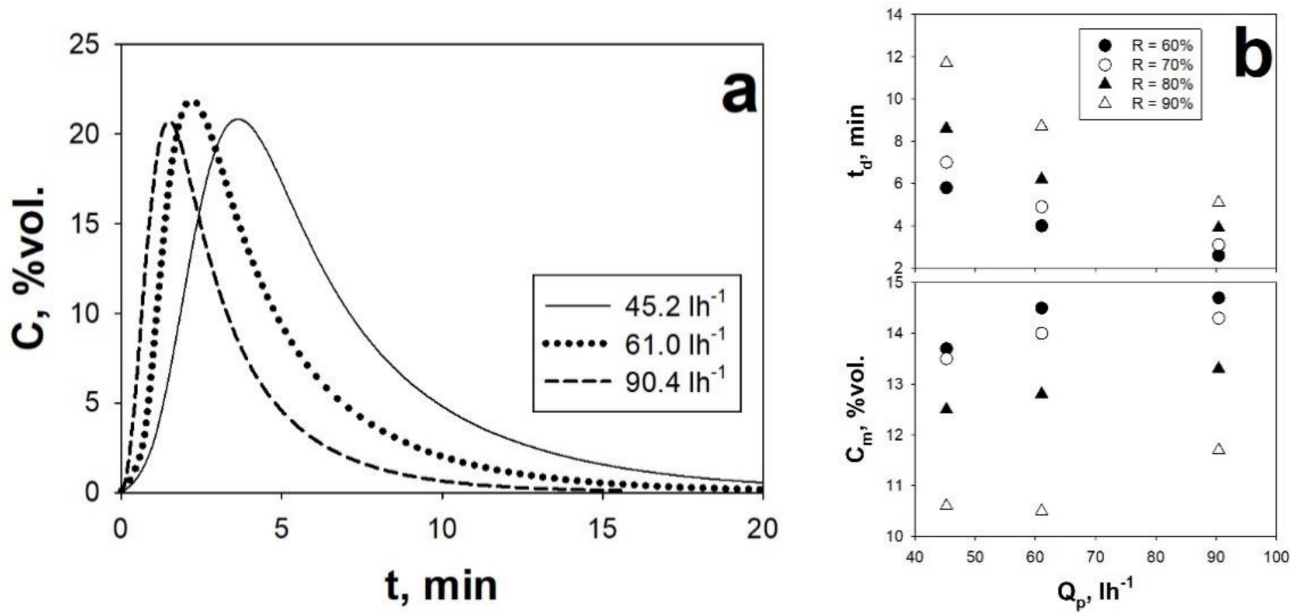

Figure 12. (a) Desorption peaks of AC Norit obtained, using the isothermal regeneration mode, under sound-assisted conditions at different $Q_{p}$ at a fixed $T_{\text {des }}\left(70{ }^{\circ} \mathrm{C}\right) .(\mathbf{b}) \mathrm{t}_{\mathrm{d}}$ and $\mathrm{C}_{\mathrm{m}}$ as functions of $\mathrm{Q}_{\mathrm{p}}$ at fixed $\mathrm{T}_{\mathrm{des}}\left(70^{\circ} \mathrm{C}\right)$ and different values of $\mathrm{R}$. Adsorption step: $\mathrm{SPL}=140 \mathrm{~dB} ; \mathrm{f}=80 \mathrm{~Hz}$; $\mathrm{Q}_{\mathrm{IN}}=67.8 \mathrm{NL} \mathrm{h}^{-1} ; \mathrm{C}_{0}=10 \mathrm{vol} . \%$. Adapted from [19] with permission.

With reference to the effect of $\mathrm{T}_{\mathrm{des}}$, the analysis of Figure $11 \mathrm{a}$ highlights that the $\mathrm{CO}_{2}$ desorption process is fastened by increasing values of $\mathrm{T}_{\mathrm{des}}$, as clearly denoted by the $\mathrm{CO}_{2}$ desorption peaks becoming higher and narrower as $\mathrm{T}_{\text {des }}$ is increased. This experimental evidence can be explained considering that at higher values of $\mathrm{T}_{\mathrm{des}}$ : (i) the thermodynamics equilibrium is shifted towards the desorption, namely the adsorption process is more and more penalized, meaning that the $\mathrm{CO}_{2}$ are more easily found in the desorbed rather than in the adsorbed state and (ii) the $\mathrm{CO}_{2}$ and $\mathrm{N}_{2}$ molecular diffusivities are increased. Then, based on the elaboration of the experimental desorption peaks, it has been highlighted in Figure $11 \mathrm{~b}$ that: (i) the time required to achieve a certain value of $\mathrm{R}$ monotonically decreases with increasing $\mathrm{T}_{\text {des }}$ and (ii) at a fixed value of $\mathrm{R}$, the concentration of the recovered $\mathrm{CO}_{2}$ stream can be remarkably improved increasing $\mathrm{T}_{\text {des }}$. Moreover, it is important to underline that, regardless of the $\mathrm{N}_{2}$ purge flow rates, values of $\mathrm{T}_{\text {des }}$ larger than $70{ }^{\circ} \mathrm{C}$ are enough to concentrate the captured $\mathrm{CO}_{2}$; indeed, as clearly shown in Figure $11 \mathrm{~b}, \mathrm{C}_{\mathrm{m}}$ is larger than $\mathrm{C}_{0}$ (10 vol.\%). 
With reference to the effect of $Q_{p}$, the analysis of Figure 12a evidences that the $\mathrm{CO}_{2}$ desorption process is fastened by increasing values of $Q_{p}$, as evidently shown by the $\mathrm{CO}_{2}$ desorption peaks becoming narrower as $Q_{p}$ is increased. However, differently from what observed with increasing $\mathrm{T}_{\text {des }}, \mathrm{Q}_{\mathrm{p}}$ has no effect on the maximum of the desorption peak. As observed for $T_{\text {des }}$, increasing values of $Q_{p}$ also positively affect the desorption rate. Then, the analysis of Figure 11b shows that: (i) the time required to achieve a certain value of $R$ monotonically decreases with increasing $Q_{p}$ and (ii) the concentration of the recovered $\mathrm{CO}_{2}$ stream achievable at a fixed $\mathrm{R}$ is only slightly affected by $\mathrm{Q}_{\mathrm{p}}$.

\subsection{Calcium Looping ( $\mathrm{CaL}$ )}

Since fine/ultrafine powders have been indicated as viable solution to overcome the limitation of the CaL, in the framework of both CCS and TCES application, the SAFB has been proposed in a CaL configuration (CaL-SAFB) as possible technology for the handling and processing of these materials. In particular, Figure 13a,b reports the results, in terms of time evolution of the outlet $\mathrm{CO}_{2}$ concentration, obtained in the SAFB, for TCES applications, and in the Seville experimental apparatus, for CCS applications, respectively.
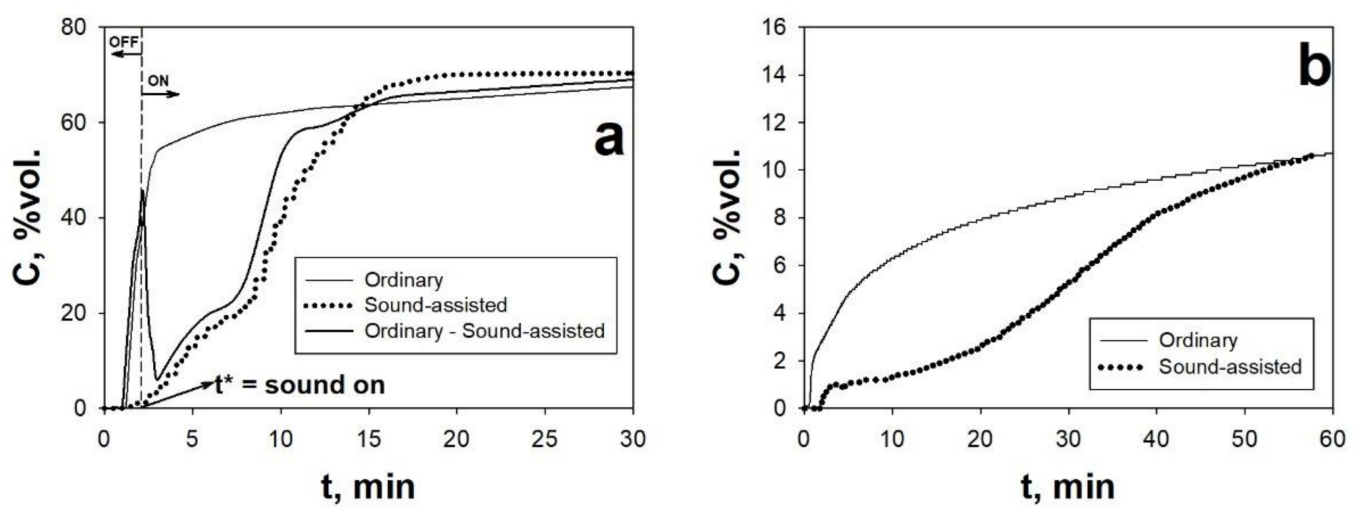

Figure 13. (a) Outlet $\mathrm{CO}_{2}$ concentration measured during carbonation in an ordinary fluidization test, a sound-assisted fluidization test and during a test in which the sound is switched on at $\mathrm{t}=\mathrm{t}^{*}$. Tests performed in the SAFB for thermochemical energy storage (TCES) applications. $\mathrm{Q}_{\mathrm{IN}}=115 \mathrm{NL} \mathrm{h}^{-1}$; $\mathrm{T}=850{ }^{\circ} \mathrm{C} ; \mathrm{C}_{0}=70 \mathrm{vol} . \%(\mathbf{b})$ Outlet $\mathrm{CO}_{2}$ concentration measured during carbonation under ordinary and sound-assisted fluidization conditions. Tests performed in the Seville experimental apparatus for Carbon Capture and Storage (CCS) applications [37]. $\mathrm{Q}_{\mathrm{IN}}: 120 \mathrm{NL} \mathrm{h}^{-1}$; Carbonation: $\mathrm{T}=650{ }^{\circ} \mathrm{C}$; $\mathrm{C}_{0}=15$ vol. $\%$ Adapted from $[5,37]$ with permission.

It is clear that when the acoustic field is applied the carbonation performances are remarkably enhanced, regardless of the specific operating conditions of CCS and TCES. Indeed, the reaction degree, namely the quantity of $\mathrm{CO}_{2}$ and $\mathrm{CaO}$ reacted, is proportional to the area between the curve and the horizontal line corresponding to the inlet $\mathrm{CO}_{2}$ concentration. Clearly, under sound-assisted fluidization conditions, this area is bigger than under ordinary conditions, meaning that more $\mathrm{CO}_{2} / \mathrm{CaO}$ has reacted. More specifically, whether the acoustic perturbation is applied or not, the variation of the slope of the $\mathrm{CO}_{2}$ concentration profile clearly evidences the existence of the two stages of the carbonation reaction, namely a fast stage under kinetic control followed by a slow diffusion controlled one. However, the time at which the transition between these two stages occurs is strongly dependent on whether the sound is applied or not. In particular, under sound-assisted fluidization conditions the transition occurs much later than under ordinary conditions. Indeed, under ordinary conditions, the $\mathrm{CaO}$ is carbonated mainly in the slow stage under diffusion control, due to the relatively fast switch from the previous fast stage of the reaction. Under sound-assisted conditions, on the contrary, the contribution of the fast kinetically controlled stage to the global carbonation conversion is remarkably enhanced, thus resulting in a general speed-up of the process. 
These experimental evidences are consistent with the observed enhancement of the fluidization quality under sound-assisted fluidization conditions (Figure 3). Indeed, as also clearly shown in Figure 14a, the fluidization quality is particularly poor under ordinary conditions, i.e., characterized by severe channeling. As a consequence, when no sound perturbation is applied, the gas-solid contact efficiency is dramatically low: a large portion of both the gaseous, i.e., $\mathrm{CO}_{2}$, and solid, i.e., $\mathrm{CaO}$, hardly takes part in the carbonation reaction due to gas by-passing, though channels, and solid agglomeration, which reduces the availability of free $\mathrm{CaO}$ surface. It is also evident from Figure 13 that the effect of the acoustic perturbation is stronger in the initial fast stage of the reaction, when the reaction is mainly due to the reaction of $\mathrm{CO}_{2}$ with the $\mathrm{CaO}$ surface and the sound can improve the gassolid contact efficiency. On the contrary, the effect of the sound becomes less evident in the slow diffusion controlled stage, when the reaction is no longer controlled by the availability of free $\mathrm{CaO}$ surface and starts to be controlled by the diffusion of the $\mathrm{CO}_{2}$ molecules through the carbonate layer. Indeed, in this stage, the improved fluidization quality and gas-solid contact efficiency yielded by the acoustic perturbation have a negligible effect on the reaction.
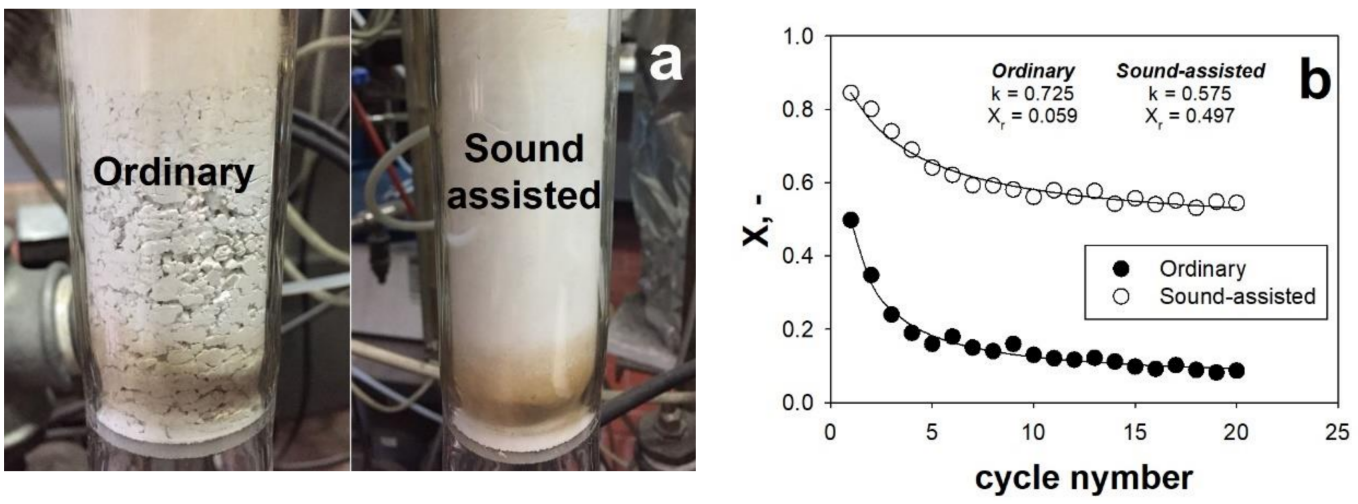

Figure 14. (a) Pictures of the fluidized bed taken during ordinary and sound-assisted fluidization tests in the SAFB; (b) evolution of the carbonation conversion with the cycle number and deactivation fit curve obtained under ordinary and sound assisted-fluidization conditions. $\mathrm{T}=850{ }^{\circ} \mathrm{C}$. $\mathrm{Q}_{\mathrm{IN}}: 115 \mathrm{NL} \mathrm{h}^{-1} ; \mathrm{C}_{0}=70$ vol.\%. Calcination: $\mathrm{T}=750{ }^{\circ} \mathrm{C} ; \mathrm{C}_{0}=0$ vol.\%. (i.e., pure $\mathrm{N}_{2}$ ). Adapted from [5] with permission.

It is also evident, from the results reported in Figure $14 \mathrm{~b}$, that the application of the acoustic field makes it possible to increase the residual carbonation conversion and reduce the rate of the natural deactivation of $\mathrm{CaO}$ due to sintering phenomena.

According to the literature $[7,83,84]$, the progressive decrease of surface due to sintering leads to a dramatic loss of $\mathrm{CaO}$ multicyclic during cyclic operations. In particular, when performed under sound-assisted conditions, the fine $\mathrm{CaO}$ sorbent shows a residual conversion as high as X20 $=0.55$ ( $\mathrm{X}$ at the 20th cycle), which is remarkably higher than the value obtained with coarser limestone particles $(\mathrm{X} 20=0.41[7,47])$ and also with $\mathrm{CaO}$ stabilized with sintering inhibitors $(X 20=0.46[7,8])$ at TCES-CSP operating conditions. This experimental evidence confirms that the employment of fine $\mathrm{CaO}$ particles can remarkably increase the carbonation performances, due to the hindrance of both sintering and pore-plugging phenomena. Besides this, it is also noteworthy that the results obtained using fine $\mathrm{CaO}$ particles in the SAFB are remarkably better than those reported for fine natural limestone tested in thermobalances [7,47]. This further confirms the capability of the SAFB configuration of getting the best performances out of fine $\mathrm{CaO}$ particles.

In regards to the calcination step, few calcination tests have been performed in the Seville experimental apparatus [37]. It was found that, even though the calcination of $\mathrm{CaCO}_{3}$ takes place at an already quick rate at temperatures as high as $900{ }^{\circ} \mathrm{C}$ under ordinary fluidization conditions, the application of sound makes it possible to accelerate it further. 


\section{Conclusions}

The present manuscript presents the sound-assisted fluidized bed reactor (SAFB), designed and set-up in Naples. In particular, the main results obtained using the SAFB are reviewed, highlighting how the acoustic affects the fluid dynamics of the system and the performances/outcomes of the specific chemical processes performed therein.

The fluidization behavior of different nano-sized and micro-sized powders has been investigated. The application of an acoustic field, characterized by proper $\mathrm{f}$ and SPL, makes it possible to either achieve an appropriate fluidization regime or enhance the fluidization quality of the powders, regardless of the specific particle size of the tested materials. In particular, while under ordinary conditions the fluidization quality is particularly poor and heterogeneous, the bed is completely fluidized, with ideal-like fluidization curves and higher values of expansion ratio, when the acoustic perturbation is applied. The effect of the acoustic parameters, i.e., SPL and f, and of the temperature has been highlighted:

- Higher SPLs lead to a general enhancement of the fluidization quality (i.e., lower values of $u_{m f}$ and $d_{a g g}$ ), whereas, an optimum range of frequency (providing minimum values of $u_{m f}$ and $d_{a g g}$ ) can be found in the proximity of to the natural frequency of the powder.

- Increasing temperatures negatively affect the fluidization quality due to the intensification of IPFs. Regardless of the powders being A or $\mathrm{C}$ type, the fluidization parameters, $u_{m f}$ and $d_{a g g}$, are increased when the temperature is increased.

The SAFB has been used in a TSA configuration (TSA-SAFB), demonstrating that fine/ultrafine powdered sorbents, regardless of their specific chemical nature, can be directly used as free-flowing powders in the TSA-SAFB also with a remarkable improvement of their adsorption/desorption performances with respect to their use in other standard reactor configurations (e.g., ordinary fluidized beds and fixed beds). The use of a proper acoustic field remarkably enhances both $\mathrm{CO}_{2}$ adsorption performances, in terms of higher values of equilibrium adsorption capacity $\left(\mathrm{q}_{\mathrm{e}}\right), \mathrm{BT}$ time $\left(\mathrm{t}_{\mathrm{b}}\right)$ and fraction of bed utilized at $t_{b}(\psi)$, and the $\mathrm{CO}_{2}$ desorption performances, in terms of higher values of $\mathrm{CO}_{2}$ recovery $(\mathrm{R})$ and $\mathrm{CO}_{2}$ purity $\left(\mathrm{C}_{\mathrm{m}}\right)$, and shorter desorption times $\left(\mathrm{t}_{\mathrm{d}}\right)$. The effect of some important operating variables on the adsorption/desorption performances has been pointed out:

- Increasing values of the adsorption temperature $\left(\mathrm{T}_{\mathrm{ads}}\right)$ negatively affects the $\mathrm{CO}_{2}$ adsorption thermodynamics, i.e., higher values of $\mathrm{T}_{\mathrm{ads}}$ lead to lower $\mathrm{q}_{\mathrm{e}}$. On the contrary, increasing values $\mathrm{T}_{\text {ads }}$ positively affect the $\mathrm{CO}_{2}$ adsorption kinetics, i.e., higher values of $T_{\text {ads }}$ lead to lower values of $\Delta t$.

- Increasing values of the $\mathrm{CO}_{2}$ partial pressure $\left(\mathrm{P}_{\mathrm{CO}_{2}}\right)$ positively affects the $\mathrm{CO}_{2}$ adsorption thermodynamics, i.e., higher values of $\mathrm{P}_{\mathrm{CO}_{2}}$ lead to higher $\mathrm{q}_{\mathrm{e}}$. Likewise, increasing values $\mathrm{P}_{\mathrm{CO}_{2}}$ positively affect the $\mathrm{CO}_{2}$ adsorption kinetics, i.e., higher values of $\mathrm{P}_{\mathrm{CO}_{2}}$ lead to lower values of $\Delta \mathrm{t}$.

- Increasing values of the desorption temperature $\left(\mathrm{T}_{\text {des }}\right)$ positively affects the $\mathrm{CO}_{2}$ desorption kinetics, i.e., for a fixed $R$, higher values of $T_{\text {des }}$ lead to shorter $t_{d}$ and higher $\mathrm{C}_{\mathrm{m}}$.

- Increasing values of $Q_{p}$ also positively affects the desorption rate, i.e., for a fixed $R$, higher values of $Q_{p}$ lead to shorter $t_{d}$ and higher $C_{m}$.

The SAFB has been proposed in a CaL configuration, CaL-SAFB, as a possible technology for the handling and processing of fine/ultrafine $\mathrm{CaO} / \mathrm{CaCO}_{3}$ particles aiming at overcoming the shortcomings/limits of the standard CaL, in the framework of both CCS and TCES application. The results obtained shows that, when the acoustic field is applied, the carbonation performances are remarkably enhanced, regardless of the specific operating conditions of CCS and TCES. In particular:

- The beneficial effect of the acoustic perturbation is much stronger in the early fast stage of the carbonation, when the reaction is mainly governed by the reaction of $\mathrm{CO}_{2}$ with the $\mathrm{CaO}$ surface and the sound can improve the gas-solid contact efficiency. 
- The acoustic perturbation also leads to the increase of the residual carbonation conversion and to the reduction of the rate of the natural deactivation of $\mathrm{CaO}$ due to sintering phenomena.

- When performed under sound-assisted conditions, the fine $\mathrm{CaO}$ particles can provide a residual conversion remarkably higher that the values reported for coarser limestone and even for $\mathrm{CaO}$ stabilized with sintering inhibitors.

Author Contributions: Conceptualization, F.R. and P.A.; methodology, F.R. and P.A.; investigation, F.R. and P.A.; writing—original draft preparation, F.R.; writing—review and editing, F.R. and P.A. All authors have read and agreed to the published version of the manuscript.

Funding: This work received no external funding.

Institutional Review Board Statement: Not applicable.

Informed Consent Statement: Not applicable.

Conflicts of Interest: The authors declare no conflict of interest.

\section{References}

1. Shabanian, J.; Jafari, R.; Chaouki, J. Fluidization of ultrafine powders. Int. Rev. Chem. Eng. 2012, 4, 16-50.

2. Raganati, F.; Chirone, R.; Ammendola, P. Gas-solid fluidization of cohesive powders. Chem. Eng. Res. Des. 2018, 133, 347-387. [CrossRef]

3. Raganati, F.; Ammendola, P.; Chirone, R. $\mathrm{CO}_{2}$ capture performances of fine solid sorbents in a sound-assisted fluidized bed. Powder Technol. 2014, 268, 347-356. [CrossRef]

4. Raganati, F.; Ammendola, P.; Chirone, R. $\mathrm{CO}_{2}$ adsorption on fine activated carbon in a sound assisted fluidized bed: Effect of sound intensity and frequency, $\mathrm{CO}_{2}$ partial pressure and fluidization velocity. Appl. Energy 2014, 113, 1269-1282. [CrossRef]

5. Raganati, F.; Chirone, R.; Ammendola, P. Calcium-looping for thermochemical energy storage in concentrating solar power applications: Evaluation of the effect of acoustic perturbation on the fluidized bed carbonation. Chem. Eng. J. 2020, 392, 123658. [CrossRef]

6. Raganati, F.; Chirone, R.; Ammendola, P. Preliminary study on sound assisted calcium looping for TCES in CSP applications. Chem. Eng. Trans. 2019, 74, 427-432. [CrossRef]

7. Ortiz, C.; Valverde, J.M.; Chacartegui, R.; Perez-Maqueda, L.A.; Giménez, P. The calcium-looping (CaCO3/CaO) process for thermochemical energy storage in concentrating solar power plants. Renew. Sustain. Energy Rev. 2019, 113, 109252. [CrossRef]

8. Sarrión, B.; Perejón, A.; Sánchez-Jiménez, P.E.; Pérez-Maqueda, L.A.; Valverde, J.M. Role of calcium looping conditions on the performance of natural and synthetic Ca-based materials for energy storage. J. $\mathrm{CO}_{2}$ Util. 2018, 28, 374-384. [CrossRef]

9. Song, C. Global challenges and strategies for control, conversion and utilization of $\mathrm{CO}_{2}$ for sustainable development involving energy, catalysis, adsorption and chemical processing. Catal. Today 2006, 115, 2-32. [CrossRef]

10. Scherer, V.; Stolten, D.; Franz, J.; Riensche, E. CCS separation techniques-Review on existing technologies and developments. Chem. Ing. Tech. 2012, 84, 1026-1040. [CrossRef]

11. Ammendola, P.; Raganati, F.; Chirone, R.; Miccio, F. Fixed bed adsorption as affected by thermodynamics and kinetics: Yellow tuff for $\mathrm{CO}_{2}$ capture. Powder Technol. 2020, 373, 446-458. [CrossRef]

12. Karl, M.; Wright, R.F.; Berglen, T.F.; Denby, B. Worst case scenario study to assess the environmental impact of amine emissions from a $\mathrm{CO}_{2}$ capture plant. Int. J. Greenh. Gas Control. 2011, 5, 439-447. [CrossRef]

13. Yu, C.-H.; Huang, C.-H.; Tan, C.-S. A review of $\mathrm{CO}_{2}$ capture by absorption and adsorption. Aerosol Air Qual. Res. 2012, 12, 745-769. [CrossRef]

14. Goel, C.; Bhunia, H.; Bajpai, P.K. Novel nitrogen enriched porous carbon adsorbents for $\mathrm{CO}_{2}$ capture: Breakthrough adsorption study. J. Environ. Chem. Eng. 2016, 4, 346-356. [CrossRef]

15. Ammendola, P.; Raganati, F.; Chirone, R. $\mathrm{CO}_{2}$ adsorption on a fine activated carbon in a sound assisted fluidized bed: Thermodynamics and kinetics. Chem. Eng. J. 2017, 322, 302-313. [CrossRef]

16. Raganati, F.; Alfe, M.; Gargiulo, V.; Chirone, R.; Ammendola, P. Kinetic study and breakthrough analysis of the hybrid physi$\mathrm{cal} /$ chemical $\mathrm{CO}_{2}$ adsorption/desorption behavior of a magnetite-based sorbent. Chem. Eng. J. 2019, 372, 526-535. [CrossRef]

17. Raganati, F.; Alfe, M.; Gargiulo, V.; Chirone, R.; Ammendola, P. Isotherms and thermodynamics of $\mathrm{CO}_{2}$ adsorption on a novel carbon-magnetite composite sorbent. Chem. Eng. Res. Des. 2018, 134, 540-552. [CrossRef]

18. Plaza, M.G.; García, S.; Rubiera, F.; Pis, J.J.; Pevida, C. Post-combustion $\mathrm{CO}_{2}$ capture with a commercial activated carbon: Comparison of different regeneration strategies. Chem. Eng. J. 2010, 163, 41-47. [CrossRef]

19. Ammendola, P.; Raganati, F.; Chirone, R. Effect of operating conditions on the $\mathrm{CO}_{2}$ recovery from a fine activated carbon by means of TSA in a fluidized bed assisted by acoustic fields. Fuel Process. Technol. 2015, 134, 494-501. [CrossRef]

20. Raganati, F.; Ammendola, P.; Chirone, R. Effect of acoustic field on $\mathrm{CO}_{2}$ desorption in a fluidized bed of fine activated carbon. Particuology 2015, 23, 8-15. [CrossRef]

21. Raganati, F.; Ammendola, P.; Chirone, R. On improving the $\mathrm{CO}_{2}$ recovery efficiency of a conventional TSA process in a sound assisted fluidized bed by separating heating and purging. Sep. Purif. Technol. 2016, 167, 24-31. [CrossRef] 
22. Elfving, J.; Bajamundi, C.; Kauppinen, J.; Sainio, T. Modelling of equilibrium working capacity of PSA, TSA and TVSA processes for $\mathrm{CO}_{2}$ adsorption under direct air capture conditions. J. $\mathrm{CO}_{2}$ Util. 2017, 22, 270-277. [CrossRef]

23. Mason, J.A.; Sumida, K.; Herm, Z.R.; Krishna, R.; Long, J.R. Evaluating metal-organic frameworks for post-combustion carbon dioxide capture via temperature swing adsorption. Energy Environ. Sci. 2011, 4, 3030-3040. [CrossRef]

24. Merel, J.; Clausse, M.; Meunier, F. Experimental investigation on $\mathrm{CO}_{2}$ post-combustion capture by indirect thermal swing adsorption using 13X and 5A zeolites. Ind. Eng. Chem. Res. 2008, 47, 209-215. [CrossRef]

25. Wang, L.; Liu, Z.; Li, P.; Yu, J.; Rodrigues, A.E. Experimental and modeling investigation on post-combustion carbon dioxide capture using zeolite 13X-APG by hybrid VTSA process. Chem. Eng. J. 2012, 197, 151-161. [CrossRef]

26. Thiruvenkatachari, R.; Su, S.; Yu, X.X.; Bae, J.-S. Application of carbon fibre composites to $\mathrm{CO}_{2}$ capture from flue gas. Int. J. Greenh. Gas Control. 2013, 13, 191-200. [CrossRef]

27. D'Alessandro, D.M.; Smit, B.; Long, J.R. Carbon dioxide capture: Prospects for new materials. Angew. Chemie. Int. Ed. 2010, 49, 6058-6082. [CrossRef]

28. Keramati, M.; Ghoreyshi, A.A. Improving $\mathrm{CO}_{2}$ adsorption onto activated carbon through functionalization by chitosan and triethylenetetramine. Phys. E. 2014, 57, 161-168. [CrossRef]

29. Gargiulo, V.; Alfè, M.; Ammendola, P.; Raganati, F.; Chirone, R. $\mathrm{CO}_{2}$ sorption on surface-modified carbonaceous support: Probing the influence of the carbon black microporosity and surface polarity. Appl. Surf. Sci. 2016, 360, 329-337. [CrossRef]

30. Jung, S.; Park, Y.-K.; Kwon, E.E. Strategic use of biochar for $\mathrm{CO}_{2}$ capture and sequestration. J. $\mathrm{CO}_{2}$ Util. 2019, 32, 128-139. [CrossRef]

31. Samanta, A.; Zhao, A.; Shimizu, G.K.H.; Sarkar, P.; Gupta, R. Post-combustion $\mathrm{CO}_{2}$ capture using solid sorbents: A review. Ind. Eng. Chem. Res. 2012, 51, 1438-1463. [CrossRef]

32. Pevida, C.; Plaza, M.G.; Arias, B.; Fermoso, J.; Rubiera, F.; Pis, J.J. Surface modification of activated carbons for $\mathrm{CO}_{2}$ capture. Appl. Surf. Sci. 2008, 254, 7165-7172. [CrossRef]

33. Dindi, A.; Quang, D.V.; Vega, L.F.; Nashef, E.; Abu-Zahra, M.R.M. Applications of fly ash for $\mathrm{CO}_{2}$ capture, utilization, and storage. J. $\mathrm{CO}_{2}$ Util. 2019, 29, 82-102. [CrossRef]

34. Goel, C.; Kaur, H.; Bhunia, H.; Bajpai, P.K. Carbon dioxide adsorption on nitrogen enriched carbon adsorbents: Experimental, kinetics, isothermal and thermodynamic studies. J. $\mathrm{CO}_{2}$ Util. 2016, 16, 50-63. [CrossRef]

35. Gargiulo, V.; Alfè, M.; Raganati, F.; Lisi, L.; Chirone, R.; Ammendola, P. BTC-based metal-organic frameworks: Correlation between relevant structural features and $\mathrm{CO}_{2}$ adsorption performances. Fuel 2018, 222, 319-326. [CrossRef]

36. Alfe, M.; Ammendola, P.; Gargiulo, V.; Raganati, F.; Chirone, R. Magnetite loaded carbon fine particles as low-cost $\mathrm{CO}_{2}$ adsorbent in a sound assisted fluidized bed. Proc. Combust. Inst. 2015, 35, 2801-2809. [CrossRef]

37. Valverde, J.M.; Raganati, F.; Quintanilla, M.A.S.; Ebri, J.M.P.; Ammendola, P.; Chirone, R. Enhancement of $\mathrm{CO}_{2}$ capture at Ca-looping conditions by high-intensity acoustic fields. Appl. Energy 2013, 111, 538-549. [CrossRef]

38. Dean, C.C.; Blamey, J.; Florin, N.H.; Al-Jeboori, M.J.; Fennell, P.S. The calcium looping cycle for $\mathrm{CO}_{2}$ capture from power generation, cement manufacture and hydrogen production. Chem. Eng. Res. Des. 2011, 89, 836-855. [CrossRef]

39. Erans, M.; Manovic, V.; Anthony, E.J. Calcium looping sorbents for $\mathrm{CO}_{2}$ capture. Appl. Energy 2016, 180, 722-742. [CrossRef]

40. Ortiz, C.; Valverde, J.M.; Chacartegui, R.; Perez-Maqueda, L.A. Carbonation of limestone derived CaO for thermochemical energy storage: From kinetics to process integration in concentrating solar plants. ACS Sustain. Chem. Eng. 2018, 6, 6404-6417. [CrossRef]

41. Valverde, J.M.; Sanchez-Jimenez, P.E.; Perez-Maqueda, L.A. Effect of heat pretreatment/recarbonation in the Ca-looping process at realistic calcination conditions. Energy Fuels. 2014, 28, 4062-4067. [CrossRef]

42. Manovic, V.; Anthony, E.J. Thermal activation of CaO-based sorbent and self-reactivation during $\mathrm{CO}_{2}$ capture looping cycles. Environ. Sci. Technol. 2008, 42, 4170-4174. Available online: http:/ / www.ncbi.nlm.nih.gov/pubmed/18589983 (accessed on 15 December 2020). [CrossRef] [PubMed]

43. Wang, Y.; Lin, S.; Suzuki, Y. Limestone calcination with $\mathrm{CO}_{2}$ capture (II): Decomposition in $\mathrm{CO}_{2} /$ steam and $\mathrm{CO}_{2} / \mathrm{N}_{2}$ atmospheres Energy Fuels 2008, 22, 2326-2331. [CrossRef]

44. Benitez-Guerrero, M.; Valverde, J.M.; Sanchez-Jimenez, P.E.; Perejon, A.; Perez-Maqueda, L.A. Calcium-Looping performance of mechanically modified Al2O3-CaO composites for energy storage and $\mathrm{CO}_{2}$ capture. Chem. Eng. J. 2018, 334, 2343-2355. [CrossRef]

45. Sánchez-Jiménez, P.E.; Valverde, J.M.; Perejón, A.; De La Calle, A.; Medina, S.; Pérez-Maqueda, L.A. Influence of ball milling on $\mathrm{CaO}$ crystal growth during limestone and dolomite calcination: Effect on $\mathrm{CO}_{2}$ capture at calcium looping conditions. Cryst. Growth Des. 2016, 16, 7025-7036. [CrossRef]

46. Antzara, A.N.; Arregi, A.; Heracleous, E.; Lemonidou, A.A. In-depth evaluation of a $\mathrm{ZrO} 2$ promoted CaO-based $\mathrm{CO}_{2}$ sorbent in fluidized bed reactor tests. Chem. Eng. J. 2018, 333, 697-711. [CrossRef]

47. Benitez-Guerrero, M.; Sarrion, B.; Perejon, A.; Sanchez-Jimenez, P.E.; Perez-Maqueda, L.A.; Manuel Valverde, J. Large-scale high-temperature solar energy storage using natural minerals. Sol. Energy Mater. Sol. Cells. 2017, 168, 14-21. [CrossRef]

48. Salaudeen, S.A.; Acharya, B.; Dutta, A. CaO-based $\mathrm{CO}_{2}$ sorbents: A review on screening, enhancement, cyclic stability, regeneration and kinetics modelling. J. $\mathrm{CO}_{2}$ Util. 2018, 23, 179-199. [CrossRef]

49. Perez-Vaquero, J.; Valverde, J.M.; Quintanilla, M.A.S. Flow properties of $\mathrm{CO}_{2}$ sorbent powders modified with nanosilica. Powder Technol. 2013, 249, 443-455. [CrossRef]

50. Valverde, J.M.; Pontiga, F.; Soria-Hoyo, C.; Quintanilla, M.A.S.; Moreno, H.; Duran, F.J.; Espin, M.J. Improving the gas-solids contact efficiency in a fluidized bed of $\mathrm{CO}_{2}$ adsorbent fine particles. Phys. Chem. Chem. Phys. 2011, 13, 14906-14909. [CrossRef] 
51. Izquierdo-Barrientos, M.A.; Sobrino, C.; Almendros-Ibáñez, J.A. Experimental heat transfer coefficients between a surface and fixed and fluidized beds with PCM. Appl. Therm. Eng. 2015, 78, 373-379. [CrossRef]

52. Wei, Z. A review of techniques for the process intensification of fluidized bed reactors. Chin. J. Chem. Eng. 2009, 17, 688-702.

53. Chirone, R.; Raganati, F.; Ammendola, P.; Barletta, D.; Lettieri, P.; Poletto, M. A comparison between interparticle forces estimated with direct powder shear testing and with sound assisted fluidization. Powder Technol. 2018, 323, 1-7. [CrossRef]

54. Raganati, F.; Chirone, R.; Ammendola, P. Effect of temperature on fluidization of geldart's group A and C powders: Role of interparticle forces. Ind. Eng. Chem. Res. 2017, 56, 12811-12821. [CrossRef]

55. Raganati, F.; Ammendola, P.; Chirone, R. Role of acoustic fields in promoting the gas-solid contact in a fluidized bed of fine particles. KONA Powder Part. J. 2015, 32, 23-40. [CrossRef]

56. Seville, J.P.K.; Willett, C.D.; Knight, P.C. Interparticle forces in fluidisation: A review. Powder Technol. 2000, 113, 261-268. [CrossRef]

57. Zeng, P.; Zhou, T.; Yang, J. Behavior of mixtures of nano-particles in magnetically assisted fluidized bed. Chem. Eng. Process. Process. Intensif. 2008, 47, 101-108. [CrossRef]

58. Yu, Q.; Dave, R.N.; Zhu, C.; Quevedo, J.A.; Pfeffer, R. Enhanced fluidization of nanoparticles in an oscillating magnetic field. AIChE J. 2005, 51, 1971-1979. [CrossRef]

59. Lepek, D.; Valverde, J.M.; Pfeffer, R.; Dave, R.N. Enhanced nanofluidization by alternating electric fields. AIChE J. 2010, 56, 54-65. [CrossRef]

60. Valverde, J.M.; Espin, M.J.; Quintanilla, M.A.S.; Castellanos, A. Electrofluidized bed of silica nanoparticles. J. Electrostat. 2009, 67, 439-444. [CrossRef]

61. Nam, C.H.; Pfeffer, R.; Dave, R.N.; Sundaresan, S. Aerated vibrofluidization of silica nanoparticles. AIChE J. 2004, 50, 1776-1785. [CrossRef]

62. Yang, J.; Zhou, T.; Song, L. Agglomerating vibro-fluidization behavior of nano-particles. Adv. Powder Technol. 2009, 20, 158-163. [CrossRef]

63. Ammendola, P.; Chirone, R. Aeration and mixing behaviours of nano-sized powders under sound vibration. Powder Technol. 2010, 201, 49-56. [CrossRef]

64. Viscusi, A.; Ammendola, P.; Astarita, A.; Raganati, F.; Scherillo, F.; Squillace, A.; Chirone, R.; Carrino, L. Aluminum foam made via a new method based on cold gas dynamic sprayed powders mixed through sound assisted fluidization technique. J. Mater. Process. Technol. 2016, 231, 265-276. [CrossRef]

65. Raganati, F.; Scherillo, F.; Squillace, A.; Chirone, R.; Ammendola, P. Improvement of the manufacturing process of tungsten carbide-cobalt hard metals by the application of sound assisted fluidization for the mixing of the powders. Ind. Eng. Chem. Res. 2018, 57, 414-424. [CrossRef]

66. Ammendola, P.; Chirone, R.; Raganati, F. Effect of mixture composition, nanoparticle density and sound intensity on mixing quality of nanopowders. Chem. Eng. Process. Process. Intensif. 2011, 50, 885-891. [CrossRef]

67. Ammendola, P.; Chirone, R.; Raganati, F. Fluidization of binary mixtures of nanoparticles under the effect of acoustic fields Adv. Powder Technol. 2011, 22, 174-183. [CrossRef]

68. Raganati, F.; Gargiulo, V.; Ammendola, P.; Alfe, M.; Chirone, R. $\mathrm{CO}_{2}$ capture performance of HKUST-1 in a sound assisted fluidized bed. Chem. Eng. J. 2014, 239, 75-86. [CrossRef]

69. Raganati, F.; Chirone, R.; Ammendola, P. $\mathrm{CO}_{2}$ capture by temperature swing adsorption: Working capacity as affected by temperature and $\mathrm{CO}_{2}$ partial pressure. Ind. Eng. Chem. Res. 2020, 59, 3593-3605. [CrossRef]

70. Chirone, R.; Massimilla, L.; Russo, S. Bubble-free fluidization of a cohesive powder in an acoustic field. Chem. Eng. Sci. 1993, 48, 41-52. [CrossRef]

71. Russo, P.; Chirone, R.; Massimilla, L.; Russo, S. The influence of the frequency of acoustic waves on sound-assisted fluidization of beds of fine particles. Powder Technol. 1995, 82, 219-230. [CrossRef]

72. Langfeldt, F.; Hoppen, H.; Gleine, W. Resonance frequencies and sound absorption of Helmholtz resonators with multiple necks. Appl. Acoust. 2019, 145, 314-319. [CrossRef]

73. Tang, P.K.; Sirignano, W.A. Theory of a generalized Helmholtz resonator. J. Sound Vib. 1973, 26, 247-262. [CrossRef]

74. Wang, Z.; Choy, Y. Acoustical coupling and radiation control of open cavity using an array of Helmholtz resonators. Mech. Syst. Signal Process 2019, 130, 632-648. [CrossRef]

75. Wen, C.Y.; Yu, Y.H. A generalized method for predicting the minimum fluidization velocity. AIChE J. 1966, 12, 610-612. [CrossRef]

76. Sánchez Jiménez, P.E.; Perejón, A.; Benítez Guerrero, M.; Valverde, J.M.; Ortiz, C.; Pérez Maqueda, L.A. High-performance and low-cost macroporous calcium oxide based materials for thermochemical energy storage in concentrated solar power plants. Appl. Energy 2019, 235, 543-552. [CrossRef]

77. Ballou, G.M. Handbook for Sound Engineers; Focal Press: Waltham, MA, USA, 2008.

78. Guo, Q.; Yang, X.; Shen, W.; Liu, H. Agglomerate size in an acoustic fluidized bed with sound assistance. Chem. Eng. Process. Process. Intensif. 2007, 46, 307-313. [CrossRef]

79. Lettieri, P.; Newton, D.; Yates, J.G. High temperature effects on the dense phase properties of gas fluidized beds. Powder Technol. 2001, 120, 34-40. [CrossRef]

80. Formisani, B.; Girimonte, R.; Pataro, G. The influence of operating temperature on the dense phase properties of bubbling fluidized beds of solids. Powder Technol. 2002, 125, 28-38. [CrossRef] 
81. Geldart, D.; Wong, A.C.Y. Fluidization of powders showing degrees of cohesiveness-II. Experiments on rates of de-aeration. Chem. Eng. Sci. 1985, 40, 653-661. [CrossRef]

82. Hu, Y.H.; Zhang, L. Amorphization of metal-organic framework MOF-5 at unusually low applied pressure. Phys. Rev. B 2010, 81, 1-5. [CrossRef]

83. Chacartegui, R.; Alovisio, A.; Ortiz, C.; Valverde, J.M.; Verda, V.; Becerra, J.A. Thermochemical energy storage of concentrated solar power by integration of the calcium looping process and a $\mathrm{CO}_{2}$ power cycle. Appl. Energy 2016, 173, 589-605. [CrossRef]

84. Ortiz, C.; Romano, M.C.; Valverde, J.M.; Binotti, M.; Chacartegui, R. Process integration of Calcium-Looping thermochemical energy storage system in concentrating solar power plants. Energy 2018, 155, 535-551. [CrossRef] 